\title{
Aerosol microphysics simulations of the Mt. Pinatubo eruption with the UM-UKCA composition-climate model
}

\author{
S. S. Dhomse ${ }^{1}$, K. M. Emmerson ${ }^{2}$, G. W. Mann ${ }^{1,3}$, N. Bellouin ${ }^{4}$, K. S. Carslaw ${ }^{1}$, M. P. Chipperfield ${ }^{1}$, R. Hommel ${ }^{5, *}$, \\ N. L. Abraham ${ }^{3,5}$, P. Telford ${ }^{3,5}$, P. Braesicke ${ }^{3,5, * *}$, M. Dalvi ${ }^{3,6}$, C. E. Johnson ${ }^{6}$, F. O' Connor ${ }^{6}$, O. Morgenstern ${ }^{7}$, \\ J. A. Pyle ${ }^{3,5}$, T. Deshler ${ }^{8}$, J. M. Zawodny ${ }^{9}$, and L. W. Thomason ${ }^{9}$ \\ ${ }^{1}$ School of Earth and Environment, University of Leeds LS2 9JT, UK \\ ${ }^{2}$ CSIRO Marine and Atmospheric Research, Aspendale, Victoria 3195, Australia \\ ${ }^{3}$ National Centre for Atmospheric Science (NCAS-Climate), UK \\ ${ }^{4}$ Department of Meteorology, University of Reading, Reading, UK \\ ${ }^{5}$ Department of Chemistry, University of Cambridge, Cambridge, UK \\ ${ }^{6}$ Met Office, Exeter, UK \\ ${ }^{7}$ National Institute of Water and Atmospheric Research (NIWA), Lauder, New Zealand \\ ${ }^{8}$ University of Wyoming, Wyoming, USA \\ ${ }^{9}$ NASA Langley Research Center, Hampton, Virginia, USA \\ *now at: IUP, University of Bremen, Bremen, Germany \\ ** now at: IMK-ASF Karlsruhe Institute of Technology, Karlsruhe, Germany
}

Correspondence to: S. S. Dhomse (s.s.dhomse@ leeds.ac.uk)

Received: 15 December 2013 - Published in Atmos. Chem. Phys. Discuss.: 28 January 2014

Revised: 16 September 2014 - Accepted: 16 September 2014 - Published: 24 October 2014

\begin{abstract}
We use a stratosphere-troposphere compositionclimate model with interactive sulfur chemistry and aerosol microphysics, to investigate the effect of the 1991 Mount Pinatubo eruption on stratospheric aerosol properties. Satellite measurements indicate that shortly after the eruption, between 14 and $23 \mathrm{Tg}$ of $\mathrm{SO}_{2}$ (7 to $11.5 \mathrm{Tg}$ of sulfur) was present in the tropical stratosphere. Best estimates of the peak global stratospheric aerosol burden are in the range 19 to $26 \mathrm{Tg}$, or 3.7 to $6.7 \mathrm{Tg}$ of sulfur assuming a composition of between 59 and $77 \% \mathrm{H}_{2} \mathrm{SO}_{4}$. In light of this large uncertainty range, we performed two main simulations with 10 and $20 \mathrm{Tg}$ of $\mathrm{SO}_{2}$ injected into the tropical lower stratosphere. Simulated stratospheric aerosol properties through the 1991 to 1995 period are compared against a range of available satellite and in situ measurements. Stratospheric aerosol optical depth (sAOD) and effective radius from both simulations show good qualitative agreement with the observations, with the timing of peak SAOD and decay timescale matching well with the observations in the tropics and mid-latitudes. However, injecting $20 \mathrm{Tg}$ gives a factor of 2 too high stratospheric aerosol mass burden compared to the satellite data, with con-
\end{abstract}

sequent strong high biases in simulated SAOD and surface area density, with the $10 \mathrm{Tg}$ injection in much better agreement. Our model cannot explain the large fraction of the injected sulfur that the satellite-derived $\mathrm{SO}_{2}$ and aerosol burdens indicate was removed within the first few months after the eruption. We suggest that either there is an additional alternative loss pathway for the $\mathrm{SO}_{2}$ not included in our model (e.g. via accommodation into ash or ice in the volcanic cloud) or that a larger proportion of the injected sulfur was removed via cross-tropopause transport than in our simulations.

We also critically evaluate the simulated evolution of the particle size distribution, comparing in detail to balloonborne optical particle counter (OPC) measurements from Laramie, Wyoming, USA $\left(41^{\circ} \mathrm{N}\right)$. Overall, the model captures remarkably well the complex variations in particle concentration profiles across the different OPC size channels. However, for the 19 to $27 \mathrm{~km}$ injection height-range used here, both runs have a modest high bias in the lowermost stratosphere for the finest particles (radii less than $250 \mathrm{~nm}$ ), and the decay timescale is longer in the model for these particles, with a much later return to background conditions. Also, 
whereas the $10 \mathrm{Tg}$ run compared best to the satellite measurements, a significant low bias is apparent in the coarser size channels in the volcanically perturbed lower stratosphere. Overall, our results suggest that, with appropriate calibration, aerosol microphysics models are capable of capturing the observed variation in particle size distribution in the stratosphere across both volcanically perturbed and quiescent conditions. Furthermore, additional sensitivity simulations suggest that predictions with the models are robust to uncertainties in sub-grid particle formation and nucleation rates in the stratosphere.

\section{Introduction}

Volcanic eruptions can have significant impacts on atmospheric composition and climate (e.g. McCormick et al., 1995; Robock, 2000). Powerful explosive eruptions can inject large amounts of $\mathrm{SO}_{2}$, ash, water vapour and various other chemical species directly into the stratosphere. Volcanic $\mathrm{SO}_{2}$ injected into the stratosphere is chemically converted to sulfuric acid vapour over a timescale of days to months, causing substantial new particle formation and aerosol growth by condensation. Volcanic enhancements of the stratospheric aerosol can be long lasting, with optically active particle concentrations remaining substantially enhanced for several years in the case of tropical eruptions (Deshler et al., 2003). The perturbed stratospheric aerosol alters the Earth's radiative balance with increased albedo via enhanced back-scattering of solar radiation, cooling the surface and increased absorption of terrestrial long-wave radiation, warming the stratosphere (Labitzke and McCormick, 1992). The relative magnitude of these short-wave and longwave radiative effects are strongly influenced by the aerosol particle size distribution (Lacis et al., 1992; Hansen et al., 1992).

The long-wave radiative heating induced by the thicker aerosol layer also modifies the stratospheric circulation (e.g. Young et al., 1994), leading to indirect radiative effects via dynamical changes in ozone and meridional transport, with important implications for surface climate (Robock and Mao, 1992; Graf et al., 1993). Volcanically increased aerosol surface area density (SAD) can also accelerate heterogeneous chemistry perturbing stratospheric $\mathrm{NO}_{\mathrm{y}}$ species, halogens and ozone (e.g. Solomon et al., 1996). Quantifying the net impact from these direct and indirect radiative effects is very important to better understand volcanic influences within the historical climate records.

There is an increasing recognition that having a good representation of stratospheric processes is important for climate projections (e.g. Scaife et al., 2012). However, whereas most coupled atmosphere-ocean climate models (e.g. Jones et al., 2011) that carried out historical integrations for CMIP5 (Taylor et al., 2012) included a prognostic treatment of tropo- spheric aerosol, stratospheric aerosols are treated separately. Some models impose volcanic forcings and heating rates (e.g. Stenchikov et al., 1998) or base these on prescribed time-varying aerosol optical depth climatologies (such as Sato et al., 1993). None of the CMIP5 climate models are able to capture the complex dynamical changes associated with large tropical eruptions (Driscoll et al., 2012). There is now an established group of composition-climate models (CCMs) which simulate stratospheric chemistry with interactive ozone radiative effects (e.g. SPARC, 2010), but few include prognostic treatment of stratospheric aerosol. Even relatively modest changes in stratospheric aerosol can exert a significant radiative forcing (e.g. Solomon et al., 2011) and expected future changes in stratospheric circulation further motivate the need for interactive stratospheric aerosol in climate models.

We use the stratosphere-troposphere composition-climate model UM-UKCA (Unified Model - UK Chemistry and Aerosol) to simulate stratospheric aerosol interactively. The model includes the GLOMAP-mode aerosol scheme and calculates aerosol optical properties online and consistently with the 3-D evolution of the particle size distribution, as driven by the underlying microphysical processes. We use the 1991 Mt Pinatubo eruption as a test case to examine simulated aerosol properties comparing to a range of satellite and in situ observations covering the background, volcanic perturbation and decay periods. Pinatubo erupted in the Philippines $\left(15.1^{\circ} \mathrm{N}, 120.4^{\circ} \mathrm{E}\right)$ on 15 June 1991 and was the largest tropical eruption since Krakatoa 1883. Based on column $\mathrm{SO}_{2}$ mass loadings derived from ultraviolet radiation measurements from the Total Ozone Monitoring Spectrometer (TOMS) instrument, Bluth et al. (1992) estimated that the eruption injected approximately $20 \mathrm{Tg}$ into the tropical stratosphere. Guo et al. (2004a) re-evaluated the post-Pinatubo TOMS data, and also analysed measurements from the Television Infra-red Observation Satellite Vertical Sounder (TOVS), finding total $\mathrm{SO}_{2}$ released to be in the range 14 to $23 \mathrm{Tg}$ ( 7 to $11.5 \mathrm{Tg}$ of sulfur).

Assuming a $50 \%$ conversion of $\mathrm{SO}_{2}$ to sulfuric acid by July and using an assumed size distribution and composition to convert the Stratospheric Aerosol and Gas Experiment II (SAGE II) satellite measurements of aerosol extinction, McCormick and Veiga (1992) estimated that the total global aerosol loading was increased by 20 to $30 \mathrm{Tg}$. Baran and Foot (1994) used infrared satellite measurements from the Highresolution Infrared Radiation Sounder (HIRS) instrument to derive a time series of the global stratospheric aerosol mass loading, finding a peak of $21 \mathrm{Tg}$ in September 1991 with values in excess of $15 \mathrm{Tg}$ persisting until November 1992 and much earlier and steeper decay in the tropics than in Northern Hemisphere (NH) mid-latitudes. Lambert et al. (1993) found a peak aerosol loading of 19 to $26 \mathrm{Tg}$ from the Improved Stratospheric and Mesospheric Sounder (ISAMS) measurements, which assuming the aerosol composition ranges from 59 to $77 \%$ sulfuric acid (Grainger et al., 1993), translates 
into a peak aerosol sulfur burden uncertainty range of 3.7 to $6.7 \mathrm{Tg}$ of sulfur. Taken together, these findings suggest that a large proportion of the sulfur was removed from the stratosphere within the first few months after the eruption, with potential loss pathways involving sedimentation, crosstropopause transport out of the stratosphere (Deshler, 2008) or enhanced removal via interactions with ash or ice in the Pinatubo cloud (Guo et al., 2004b). Monthly balloon soundings of total and size-resolved particle concentrations carried out at Laramie, Wyoming (e.g. Deshler, 1994) showed that although substantially enhanced particle concentrations were detected in the lowermost stratosphere by mid-July, the main part of the volcanic plume was only transported to NH midlatitudes several months later.

There have been many previous global modelling studies to investigate the evolution of the stratospheric aerosol following the Pinatubo eruption. However, most have used aerosol schemes that simulate only the evolution of aerosol mass, prescribing a fixed particle size distribution for sedimentation and radiative effects (e.g. Timmreck et al., 1999; Oman et al., 2006; Aquila et al., 2012). However, sizeresolved stratospheric aerosol modules which include microphysical processes such as new particle formation, coagulation and condensation have also been developed. The first Pinatubo aerosol microphysics simulations were carried out in 2-D models (Bekki and Pyle, 1994; Weisenstein et al., 1997) with single-moment sectional schemes where mass in numerous size bins is transported. More recently, several 3D general circulation models (GCMs) with aerosol microphysics schemes have also been developed, to predict sedimentation and changes in radiative properties in conjunction with an evolving stratospheric particle size distribution (e.g. Timmreck, 2001; Toohey et al., 2011; English et al., 2012, 2013).

Although there have been this development of more sophisticated models, most of these studies evaluated their simulations against a limited set of observational data sets, primarily aerosol optical depths (AODs) derived using Advanced Very High Resolution Radiometer (AVHRR) and SAGE II measurements. Using a mass-based prognostic stratospheric aerosol module in a middle-atmosphere version of the ECHAM4 climate model, Timmreck et al. (1999) showed that the two distinct maxima in AOD apparent in AVHRR- and SAGE-II-based stratospheric aerosol optical depth (sAOD) could be simulated, but the model failed to simulate the observed slow sAOD decay in the tropics after the peak. Similarly, Pitari and Mancini (2002) used a GCM coupled to a global chemistry transport model with interactive aerosol microphysics, and could simulate $\mathrm{SH}$ sAOD reasonable well, but $\mathrm{NH}$ and tropical sAOD was biased low. Aquila et al. (2012) used a GCM with a massbased aerosol scheme radiatively coupled to the model dynamics. They found that simulated SAOD was higher than both AVHRR and SAGE II during the first few months, but showed very good agreement during the later phase. Using a sectional aerosol microphysics module with injection altitude between 15.5 and $27 \mathrm{~km}$, English et al. (2013) achieved good agreement with SAGE- and AVHRR-observed SAOD in $\mathrm{NH}$ mid-latitudes for the first 12 months after the eruption but too rapid decay in sAOD through later months. They also compared model aerosol effective radius ( $\left.R_{\text {eff }}\right)$ evolution against observations from SAGE II and in situ measurements (for e.g. Russell et al., 1996; Bauman et al., 2003), finding that peak values in the model $\mathrm{NH}$ tropical stratosphere occurred earlier than in the observations. Some of these modelobservation biases in earlier studies may be linked with the transport-related issues (e.g. the lack of a quasi-biennial oscillation, QBO) in the underlying GCM, whereas some may be linked to the simplified treatment of the particle size distribution. Other causes such as interactions with ash, or missing minor eruptions such as Mount Hudson in Chile (September 1991) have also been suggested.

Although they have near-global spatial extent, satellite measurements of sAOD and $R_{\text {eff }}$ constrain only integrated stratospheric aerosol properties over the full particle size range. Balloon-borne measurements (e.g. Deshler, 1994) enable a closer examination of the particle size distribution, but are available at only a small number of sites.

Here, we use both satellite and balloon-borne measurements to evaluate the UM-UKCA simulated stratospheric aerosol properties, and seek to provide a wider set of observational constraints for the models and to better understand how the stratospheric aerosol layer was perturbed. In Sect. 2 we describe the model, including the experimental set-up and the developments to the aerosol and chemistry schemes which extend its applicability to both stratospheric and tropospheric conditions. Section 3 describes the measurements that are used to evaluate the model. Results and discussion about potential causes of model-observation biases are presented in Sect. 4 and 5, respectively. Summary and major conclusions are presented in Sect. 6.

\section{Model description}

We use the stratospheric chemistry configuration of UMUKCA (Morgenstern et al., 2009) which here is an extended configuration of the high-top version of the third-generation Hadley Centre Global Environmental Model (HadGEM3) (Hewitt et al., 2011) as used by Braesicke et al. (2013) and Telford et al. (2013). Although UM-UKCA can be run with fully coupled aerosol-chemistry dynamics with online radiative effects from the simulated aerosol, $\mathrm{O}_{3}, \mathrm{CH}_{4}, \mathrm{~N}_{2} \mathrm{O}$ and other gases, here only the simulated $\mathrm{O}_{3}$ is radiatively coupled. Sea-surface temperature and sea-ice fields are prescribed from the AMIP time-varying data set (Hurrell et al., 2008). The simulations are carried out at N48 horizontal resolution $\left(2.5^{\circ}\right.$ and $3.75^{\circ}$ in latitude and longitude) with 60 vertical hybrid-height levels from the surface to $84 \mathrm{~km}$. 
In order to simulate stratospheric aerosol precursor gas phase species, we have extended the existing UM-UKCA stratospheric chemistry scheme to also include sulfur chemistry (see Sect. 2.1). The coupling to the GLOMAP-mode aerosol microphysics module (Mann et al., 2010), and its adaptation for stratospheric conditions, is described in Sect. 2.2. Surface emissions of $\mathrm{NO}_{\mathrm{x}}, \mathrm{CO}$ and $\mathrm{HCHO}$ are from the RCP 4.5 scenario. Lower boundary conditions are applied for $\mathrm{CH}_{4}, \mathrm{~N}_{2} \mathrm{O}, \mathrm{CFC}-11\left(\mathrm{CFCl}_{3}\right)$ and $\mathrm{CFC}-12\left(\mathrm{CF}_{2} \mathrm{Cl}_{2}\right)$ according to WMO (2011). Heterogeneous chemical reactions use time-varying prescribed aerosol surface area density produced for the SPARC Assessment of the Stratospheric Aerosols Properties report (SPARC, 2006). We include surface and elevated emissions of anthropogenic $\mathrm{SO}_{2}$ from Lamarque et al. (2010) with also a 3-D source from passively degassing volcanoes from Andres and Kasgnoc (1998). DMS emissions are simulated interactively using a seawater concentration climatology of Kettle and Andreae (2000) with the sea-air exchange function of Liss and Merlivat (1986). For OCS, which has a tropospheric lifetime of about 2 years (Montzka et al., 2007), we do not include an emissions source, but instead apply a fixed lower boundary condition of $550 \mathrm{pptm}$.

\subsection{Stratospheric chemistry extended to include the sulfur cycle}

The existing UM-UKCA stratospheric chemistry scheme (Morgenstern et al., 2009) covers the oxidation of $\mathrm{CH}_{4}$ and $\mathrm{CO}$, with chlorine and bromine chemistry and their interaction with $\mathrm{HO}_{\mathrm{x}}, \mathrm{NO}_{\mathrm{x}}$ and $\mathrm{O}_{\mathrm{x}}$ cycles including heterogeneous reactions on polar stratospheric clouds (PSCs) and liquid sulfate aerosols (Chipperfield and Pyle, 1998). Here, we have extended the scheme to also include a stratospheric aerosol precursor chemistry scheme (Weisenstein et al., 1997) with updates to reaction rates from Sander et al. (2006), see Table 1 . The added chemistry includes the steady background source of $\mathrm{SO}_{2}$ from OCS, which principally maintains the stratospheric aerosol during volcanically quiescent periods (e.g. Carslaw and Kärcher, 2006). Also included are photolysis reactions for $\mathrm{H}_{2} \mathrm{SO}_{4}$ and $\mathrm{SO}_{3}$, which occur above about $30 \mathrm{~km}$ and lead to a reservoir of $\mathrm{SO}_{2}$ building up during polar winter, enabling new particle formation in the polar lower stratosphere during spring (Mills et al., 2005). The chemistry is integrated with the ASAD chemical integration package (Carver et al., 1997) with the Newton-Raphson sparse matrix solver from Wild et al. (2000). Photolysis rates are calculated using the FAST-JX online photolysis (Neu et al., 2007) following the implementation described in Telford et al. (2013). The cross-section of $\mathrm{H}_{2} \mathrm{SO}_{4}$ is assumed analogous to the cross-section of $\mathrm{HCl}(\times 0.016)$ following the method of Bekki and Pyle (1992). Aqueous sulfate production in (tropospheric) liquid clouds is also passed to the GLOMAP module for growth of accumulation and coarse soluble particles.

\subsection{The aerosol microphysics module adapted for the stratosphere}

The GLOMAP aerosol microphysics module was initially developed as a component of the TOMCAT 3-D offline Chemical Transport Model (Chipperfield, 2006) with both 2-moment sectional (Spracklen et al., 2005) and 2-moment modal versions (Mann et al., 2010) available. The computationally faster modal scheme (GLOMAP-mode) was specifically designed for longer integrations within UM-UKCA and applies the same aerosol microphysics representations as the sectional scheme but with the size distribution parameterised into seven log-normal modes, being similar in framework to that used in ECHAM-HAM (e.g. Stier et al., 2005). The GLOMAP-mode scheme produces aerosol properties in good agreement with the more sophisticated sectional scheme under most tropospheric conditions (Mann et al., 2012).

Since this study investigates the evolution of the stratospheric aerosol layer after Pinatubo, we use only the four soluble modes and treat only sulfate and sea salt components - the latter included to give reasonable representation of tropospheric aerosol optical properties. For this work, the model approaches for water uptake, particle density, vapour condensation and new particle formation have been adapted to be applicable across stratospheric and tropospheric conditions. In the following sections, we briefly describe these updates.

\subsubsection{Water uptake}

In the standard version of GLOMAP-mode described by Mann et al. (2010), water uptake is calculated using ZSR (Zdanovskii, 1948; Stokes and Robinson, 1966), which is not applicable in stratosphere conditions. At pressures below 150 $\mathrm{hPa}$ we therefore instead use the expression of Carslaw et al. (1995) to provide the aerosol water content. At $225 \mathrm{~K}$ and $101 \mathrm{hPa}$, the composition of the solution is $74.5 \% \mathrm{H}_{2} \mathrm{SO}_{4}$ and $25.5 \%$ water, approximating the $75 \%$ weight fraction assumed in some studies (e.g. Stenchikov et al., 1998; Oman et al., 2006).

\subsubsection{Particle density}

As composition of the aqueous sulfuric acid solution droplets also affects their density, we modified GLOMAP-mode for the stratosphere. For pressures lower than $150 \mathrm{hPa}$, density values for each mode are replaced with values from a lookup table based on the measurements of Martin et al. (2000) as a function of the sulfuric acid weight-fraction.

\subsubsection{Condensation and vapour pressure of $\mathrm{H}_{2} \mathrm{SO}_{4}$}

In all previous versions of the GLOMAP aerosol module, gas-to-particle transfer of $\mathrm{H}_{2} \mathrm{SO}_{4}$ occurs assuming zero vapour pressure, i.e. the transfer is represented as a condensation process. Although this approach is entirely appropriate 
Table 1. Additional sulfur chemistry reactions and rates within UM-UKCA, W= Weisenstein et al. (1997), JPL= Sander et al. (2006), K03 = Kreidenweis et al. (2003).

\begin{tabular}{lll}
\hline & Rate & Reference \\
\hline $\mathrm{DMS}+\mathrm{O}\left({ }^{3} \mathrm{P}\right) \rightarrow \mathrm{SO}_{2}+2 \mathrm{CH}_{3} \mathrm{O}_{2}$ & $1.3 \times 10^{-11} \exp (410 / T)$ & $\mathrm{W}, \mathrm{JPL}$ \\
$\mathrm{DMS}+\mathrm{OH} \rightarrow \mathrm{SO}_{2}+\mathrm{CH}_{3} \mathrm{O}_{2}+\mathrm{HCHO}$ & $1.2 \times 10^{-11} \exp (-260 / T)$ & $\mathrm{W}$ \\
$\mathrm{DMS}+\mathrm{OH} \rightarrow \mathrm{SO}_{2}+\mathrm{CH}_{3} \mathrm{O}_{2}$ & $3.04 \times 10^{-12} \exp (350 / T) \cdot(\gamma / 1+\gamma)$ & $\mathrm{W}$ \\
& $\gamma=5.53 \times 10^{-31} \exp (7460 / T) \times\left[\mathrm{O}_{2}\right]$ & \\
$\mathrm{DMS}+\mathrm{NO}_{3} \rightarrow \mathrm{SO}_{2}+\mathrm{HNO}_{3}+\mathrm{CH}_{3} \mathrm{O}_{2}+\mathrm{HCHO}$ & $1.9 \times 10^{-13} \exp (500 / T)$ & $\mathrm{W}$ \\
$\mathrm{OCS}+\mathrm{O}\left({ }^{3} \mathrm{P}\right) \rightarrow \mathrm{CO}+\mathrm{SO}_{2}$ & $2.1 \times 10^{-11} \exp (-2200 / T)$ & $\mathrm{W}, \mathrm{JPL}$ \\
$\mathrm{OCS}+\mathrm{OH} \rightarrow \mathrm{CO}_{2}+\mathrm{SO}_{2}$ & $1.1 \times 10^{-13} \exp (-1200 / T)$ & W, JPL \\
$\mathrm{SO}_{2}+\mathrm{OH}+M \rightarrow \mathrm{SO}_{3}+\mathrm{HO}_{2}$ & $k(T)=\frac{A}{1+B} \times 0.6^{\left(1+(\log B)^{2}\right)^{-1}}$ & W \\
& $A=3.0 \times 10^{-31} \times(300 / T)^{3.3}$ & \\
& $B=A / 1.5 \times 10^{-12}$ & \\
$\mathrm{SO}_{2}+\mathrm{O}_{3} \rightarrow \mathrm{SO}_{3}$ & $3.0 \times 10^{-12} \exp (-7000 / T)$ & W, JPL \\
$\mathrm{SO}_{3}+\mathrm{H}_{2} \mathrm{O} \rightarrow \mathrm{H}_{2} \mathrm{SO}_{4}$ & $8.5 \times 10^{-41} \exp (6540 / T) \cdot\left[\mathrm{H}_{2} \mathrm{O}\right]$ & JPL \\
$\mathrm{SO}_{2}+\mathrm{H}_{2} \mathrm{O}_{2}$ aqueous & $\mathrm{SO}_{4}$ & $\mathrm{~K} 03$ \\
$\mathrm{OCS}_{h} h v \rightarrow \mathrm{CO}+\mathrm{SO}_{2}$ & Photolysis & W \\
$\mathrm{H}_{2} \mathrm{SO}_{4}+h v \rightarrow \mathrm{SO}_{3}+\mathrm{H}_{2} \mathrm{O}$ & Photolysis & W \\
$\left.\mathrm{SO}_{3}+h v \rightarrow \mathrm{SO}_{2}+\mathrm{O}^{3} \mathrm{P}\right)$ & Photolysis & W \\
\hline
\end{tabular}

in tropospheric conditions, above $\sim 25-30 \mathrm{~km}$, the vapour pressure of $\mathrm{H}_{2} \mathrm{SO}_{4}\left(p_{\mathrm{H}_{2} \mathrm{SO}_{4}}\right)$ becomes significant as the temperature increases in the stratosphere and above $\sim 35 \mathrm{~km}$ the sulfuric acid droplets rapidly evaporate (Hamill et al., 1997; Hommel et al., 2011).

We therefore now calculate $p_{\mathrm{H}_{2} \mathrm{SO}_{4}}$ online in the model following Kulmala and Laaksonen (1990) and the condensation rates are calculated consistently with the difference between the vapour pressure and the gas phase partial pressure. We also apply a simple approach to particle evaporation whereby if the ambient gas phase $\mathrm{H}_{2} \mathrm{SO}_{4}$ partial pressure is less than $p_{\mathrm{H}_{2} \mathrm{SO}_{4}}$, the number concentration for all modes is reduced at a fast decay rate of $50 \%$ per condensation time step, which corresponds to an e-folding timescale of around 17 min.

\subsubsection{New particle formation}

Previous versions of GLOMAP (e.g. Mann et al., 2010) formed new $\mathrm{H}_{2} \mathrm{SO}_{4}-\mathrm{H}_{2} \mathrm{O}$ particles based on the Kulmala et al. (1998) parameterisation for binary homogeneous nucleation. This is only applicable at temperatures in the range 233-298 K. Vehkamäki et al. (2002) suggested that conditions for nucleation are also favourable at $\sim 200 \mathrm{~K}$ in the upper tropical troposphere and they updated the Kulmala et al. (1998) parameterisation to be applicable down to lower temperatures and humidities. To allow GLOMAP-mode to be applied in both tropospheric and stratospheric conditions, we have incorporated the Vehkamäki et al. (2002) parameterisation, and used it within the recommended ranges of temperature $(190$ to $305 \mathrm{~K})$ and $\mathrm{H}_{2} \mathrm{SO}_{4}$ concentration $\left(10^{4}\right.$ to $\left.10^{11} \mathrm{~cm}^{-3}\right)$. Note that we also use the expression of Kermi- nen and Kulmala (2002) to convert the cluster nucleation rate from Vehkamäki et al. (2002) into an "apparent nucleation rate" at $3 \mathrm{~nm}$. The nucleation rate is set to zero in subsaturated conditions.

\subsubsection{Size distribution}

Balloon-borne optical particle counter and condensation nucleus counter measurements in the mid-latitude stratosphere in the 1990s (e.g. Deshler et al., 2003) suggest a bimodal size distribution with the first mode at about $50-150 \mathrm{~nm}$ radius with geometric standard deviation $\left(\sigma_{g}\right)$ between 1.6 and 1.8 and a larger much narrower mode $\left(\sigma_{g} \sim 1.2\right)$ at around $300-800 \mathrm{~nm}$ radius that is weak in volcanically quiescent conditions but much stronger (in number) following the Pinatubo eruption (e.g. Carslaw and Kärcher, 2006). For example Deshler et al. (2003) show that in March 1993 (21 months after the Pinatubo eruption), in the NH midlatitude lower stratosphere there was a $6 \mathrm{~km}$ layer $(12-18 \mathrm{~km})$ with the number concentration of particles with radii larger than $500 \mathrm{~nm}$ greater than $1 \mathrm{~cm}^{-3}$. Such coarse particles have grown from their original size of around $1 \mathrm{~nm}$ due to coagulation and gas-to-particle transfer of sulfuric acid. Modal microphysics schemes such as GLOMAP-mode represent this condensational and coagulative growth, but must use a technique referred to as "mode-merging" (e.g. Binkowski and Roselle, 2003) to transfer particles to adjacent larger modes following strong growth. In the case of a large volcanic eruption, the mode-merging may transfer particles first from the nucleation mode to the soluble Aitken mode, and following further growth up to the soluble accumulation mode and then to the soluble coarse mode. In each case, when particles 
are received from the adjacent smaller mode, the transferred number and mass is added to that existing in the mode, with the mean size reformulated reformulated consistently with the $\sigma_{g}$ value for the mode.

Kokkola et al. (2009) compared size distributions simulated by a modal and three sectional schemes in a box model. While the four models agreed well in background stratospheric conditions, in volcanically perturbed conditions, the size distributions were found to be better represented with narrower mode widths. In particular, with the original coarse mode $\sigma_{g}$ of 2.0 , they found the modal scheme overpredicted the $R_{\text {eff }}$ compared to a reference sectional scheme with a large number of bins. Niemeier et al. (2009) used an improved version of the same modal microphysics scheme whereby $\sigma_{g}$ for the accumulation soluble mode was reduced to 1.2 and the coarse mode was deactivated.

Here we are applying the modal GLOMAP scheme to volcanically perturbed stratospheric conditions, and also using the same modes to represent tropospheric aerosol. In the troposphere, the coarse soluble mode in GLOMAP-mode almost exclusively contains sea-salt, and the scheme follows Wilson et al. (2001) and Vignati et al. (2004) in using a value of 2.0 for $\sigma_{g}$ in this mode, which are based on values given in D'Almeida et al. (1991).

To ensure the size distribution and vertical profile of the simulated coarse sea-salt particles is retained as evaluated in previous model versions (Mann et al., 2012), we retain the $\sigma_{g}$ value of 2.0 for the coarse soluble mode. However, we now de-activate mode-merging between the accumulation and coarse soluble modes, which allows the accumulation soluble mode to continue to grow larger than 1 micron diameter in strongly perturbed conditions. We also retain the $\sigma_{g}$ value of 1.4 for the soluble accumulation mode in GLOMAPmode, as reduced by Mann et al. (2012) from the value of 1.59 used in Mann et al. (2010), to better compare with size distributions simulated by the sectional scheme and from observations. The $\sigma_{g}=1.59$ values for the nucleation and Aitken modes are also retained.

\subsection{Experimental setup}

For this study, we carried out several 5-year model integrations, as summarised in Table 2. In addition to a background run (C_noPinatubo) without any Pinatubo emission, two reference simulations were carried out with 20 (A_Control20) and $10 \mathrm{Tg}$ (B_Control10) of $\mathrm{SO}_{2}$ injected into the tropical stratosphere on 15 June 1991 between 19 and $27 \mathrm{~km}$. To ensure we closely match the initial spatial distribution of the aerosol cloud, we inject the $\mathrm{SO}_{2}$ across the eight model grid boxes between $0-20^{\circ} \mathrm{N}$ along $120.5^{\circ} \mathrm{E}$. We emit $3 \%$ of the $\mathrm{SO}_{2}$ mass from Pinatubo directly as sulfuric acid particles (assumed to form at the sub-grid scale) with half emitted with assumed geometric mean radius of 15 and $40 \mathrm{~nm}$ as in Spracklen et al. (2005). For all the simulations the entire set of tracers were initialised from fields after 8 years spin-up.
The spin-up run started from zero aerosol and gas phase sulfur species, with other gases initialised from the UM-UKCA REF-C1 integration from the SPARC Lifetimes of Stratospheric Ozone-Depleting Substances, Their Replacements, and Related Species report (SPARC, 2013), representative of 1990 conditions.

To assess the robustness of the model to uncertainties in particle formation processes, which are known to be considerable uncertain in the stratosphere, we also carried out two sensitivity simulations with are as run B_Control10, but we switch off the sub-grid particle source (primary sulfate emission) from Pinatubo (D_noPrimary 10) and reduce the nucleation rate (E_ScaledStNuc10) in the stratosphere by a factor of 2 (by multiplying it with 0.01 ).

\section{Measurements}

To evaluate the UM-UKCA simulations, we use measurements from the SAGE II instrument (McCormick and Veiga, 1992), which was launched on the Earth Radiation Budget Satellite (ERBS) in 1984. SAGE II was a seven-channel sun photometer operated in solar occultation mode with a vertical resolution of about $0.5 \mathrm{~km}$. Spectral windows were centred at 385, 448, 453, 525, 600, 940 and $1020 \mathrm{~nm}$. For evaluating the model stratospheric aerosol optical depth, we use the gap-filled SAGE II (V6.2) product (Hamill et al., 2006) produced for ASAP (Assessment of Stratospheric Aerosol Properties SPARC, 2006). Simulated aerosol extinction is compared against the recently updated version (V7.0) of the SAGE II data (Damadeo et al., 2013). We also compare to the SAGE-derived SAD product (Thomason et al., 1997) that is obtained from http://www.sparc-climate.org/ data-center/data-access/asap/. Simulated SAD is also compared against the recently available SAD data (Arfeuille et al., 2013) which was created using SAGE II V7.0 data, and is provided for the Chemistry Climate Model Initiative (CCMI) simulations. Further evaluation of the post-Pinatubo simulated SAOD evolution was carried out by comparing to that measured by the Advanced Very High Resolution Radiometer (AVHRR/2), which was onboard on the National Oceanic and Atmospheric Administration (NOAA/11) satellite. For details see http://www.nsof.class.noaa.gov/ release/data_available/avhrr/index.htm. The AVHRR instrument measures the reflectance of the Earth in five spectral bands centred around 0.6, 0.9, 3.5, 11 and $12 \mu \mathrm{m}$.

To examine the simulated particle size distribution that underpins the model aerosol optical properties, we also compare to profile measurements of size-resolved number concentration made at Laramie, USA (Deshler et al., 2003). The balloon-borne system includes a condensation nucleus counter (CNC) to measure the concentrations of particles larger than $10 \mathrm{~nm}$ and an optical particle counter (OPC, Deshler et al., 1992) to measure size-resolved particle concentrations in several size ranges in the accumulation and 
Table 2. Microphysical parameter settings used in model simulations.

\begin{tabular}{lllc}
\hline Run & $\begin{array}{l}\mathrm{SO}_{2} \\
\text { injection }\end{array}$ & Nucleation & $\begin{array}{c}\text { Sub-grid primary } \\
\text { sulphate emission }\end{array}$ \\
\hline A_Control20 & $20 \mathrm{Tg}(19-27 \mathrm{~km})$ & Standard & Yes \\
B_Control10 & $10 \mathrm{Tg}(19-27 \mathrm{~km})$ & Standard & Yes \\
C_noPinatubo & No & Standard & Yes \\
D_noPrimary10 & $10 \mathrm{Tg}(19-27 \mathrm{~km})$ & Standard & No \\
E_ScaledStNuc10 & $10 \mathrm{Tg}(19-27 \mathrm{~km})$ & $\times 0.01$ in stratosphere & Yes \\
\hline
\end{tabular}

coarse regions of the size spectrum. The OPC is a light counter to derive integrated size distribution from measured aerosol scattering in the forward direction. The standard OPC design gives integral number concentrations larger than $150 \mathrm{~nm}$ and $250 \mathrm{~nm}$ radius, and has been used in balloon sounding measurements of stratospheric aerosol since 1963 (Rosen, 1964), also giving important information about the stratospheric aerosol changes induced by the 1963 Mt Agung (Rosen, 1964), 1980 Mt St Helen's (Hofmann and Rosen, 1982) and 1982 El Chichón (Hofmann and Rosen, 1984) eruptions. Deshler et al. (1992) present the measurements taken in July and August 1991, with most balloon flights using this original two-channel OPC. An enhanced OPC, using an increased scattering angle, measured concentrations in eight size channels for radii larger than $150 \mathrm{~nm}$ to around 10 microns. The eight-channel OPC had been developed shortly before the eruption, and became the default measuring system a few months after the eruption (Deshler et al., 1993). The measurement capabilities were later further enhanced to measure up to 12 size ranges (see Deshler et al., 2003).

\section{Results}

Stratospheric aerosol sizes and concentrations are influenced by dynamical, chemical and microphysical processes. For example, background aerosol are formed by homogeneous nucleation of $\mathrm{H}_{2} \mathrm{SO}_{4}$ and $\mathrm{H}_{2} \mathrm{O}$, with $\mathrm{H}_{2} \mathrm{SO}_{4}$ concentrations affected by oxidation of OCS and $\mathrm{SO}_{2}$. Microphysical processes such as nucleation, condensational growth, coagulation and sedimentation along with large-scale poleward transport timescales affect stratospheric lifetimes of these aerosol. To ensure the model is fully evaluated, it is necessary to evaluate the model against a range of aerosol properties, but it is also important to assess stratospheric circulation in the model and assess the evolution of key precursor gases which influence the aerosol.

\subsection{Stratospheric dynamics in the UM-UKCA}

One of the most important factors controlling stratospheric aerosol is the stratospheric transport which is determined by the strength of the stratospheric Brewer-Dobson (BD) circulation. This circulation plays a crucial role in determin- ing the evolution of the background as well as volcanically enhanced stratospheric aerosol layer. Stronger BD circulation leads to more rapid transport of air masses (and chemical species) from the tropics to high latitudes (e.g, Weber et al. 2003; Dhomse et al. 2006). This circulation also affects aerosol removal from the stratosphere (e.g. Deshler, 2008) via stratosphere-troposphere exchange (STE, e.g. Holton et al. 1995). However, the strength of the BD circulation is also coupled with the phases of the QBO via the Holton-Tan mechanism (Holton and Tan, 1980).

Using satellite observations, Trepte and Hitchman (1992) showed the importance of the QBO phase in determining the initial dispersion of the Pinatubo plume. For the simulations presented here, the model is initialised such that the lower stratospheric winds are in the easterly phase of the QBO at the time of the eruption, as observed. Figure 1a shows the time evolution of the model monthly and zonal-mean zonal wind in the tropics $\left(15^{\circ} \mathrm{S}-15^{\circ} \mathrm{N}\right)$ against those from the ERA interim re-analysis from 1990 until 1995 (Fig. 1b, Dee et al., 2011). As in ERA interim, the model begins an easterly QBO phase in mid-1991, although the model easterlies are weaker than in ERA-interim in the lower stratosphere for the first 6 months after the eruption. Also, the model easterly QBO phase begins slightly later than in ERA-interim, continuing until around September 1993 (at $30 \mathrm{hPa}$ ), compared to around January 1993 in the re-analysis. The semi-annual oscillation in the tropical middle and upper stratosphere is also well represented in the model.

A common metric used to assess stratospheric transport in CCMs (e.g. Strahan et al., 2011) is the mean stratospheric age-of-air. Figure 1c shows the latitude and altitude distribution of the model zonal-mean age-of-air (for 1991-2000) and Fig. 1d compares the model age of air at $50 \mathrm{hPa}$ against that derived from aircraft observations of the long-lived tropospheric source gases $\mathrm{SF}_{6}$ and $\mathrm{CO}_{2}$ (Hall et al., 1999). The values from other CCMs participating in the recent SPARC Lifetime Assessment (e.g. Chipperfield et al., 2014) are also shown for reference. In the tropics, the model age-of-air agrees well with the observations, but at mid- and high latitudes there is a low bias compared to the observations; up to $1 \mathrm{yr}$ too young air at high latitudes. The low bias in midlatitude age-of-air indicates that the model may have too rapid meridional poleward transport and/or stronger STE. In 

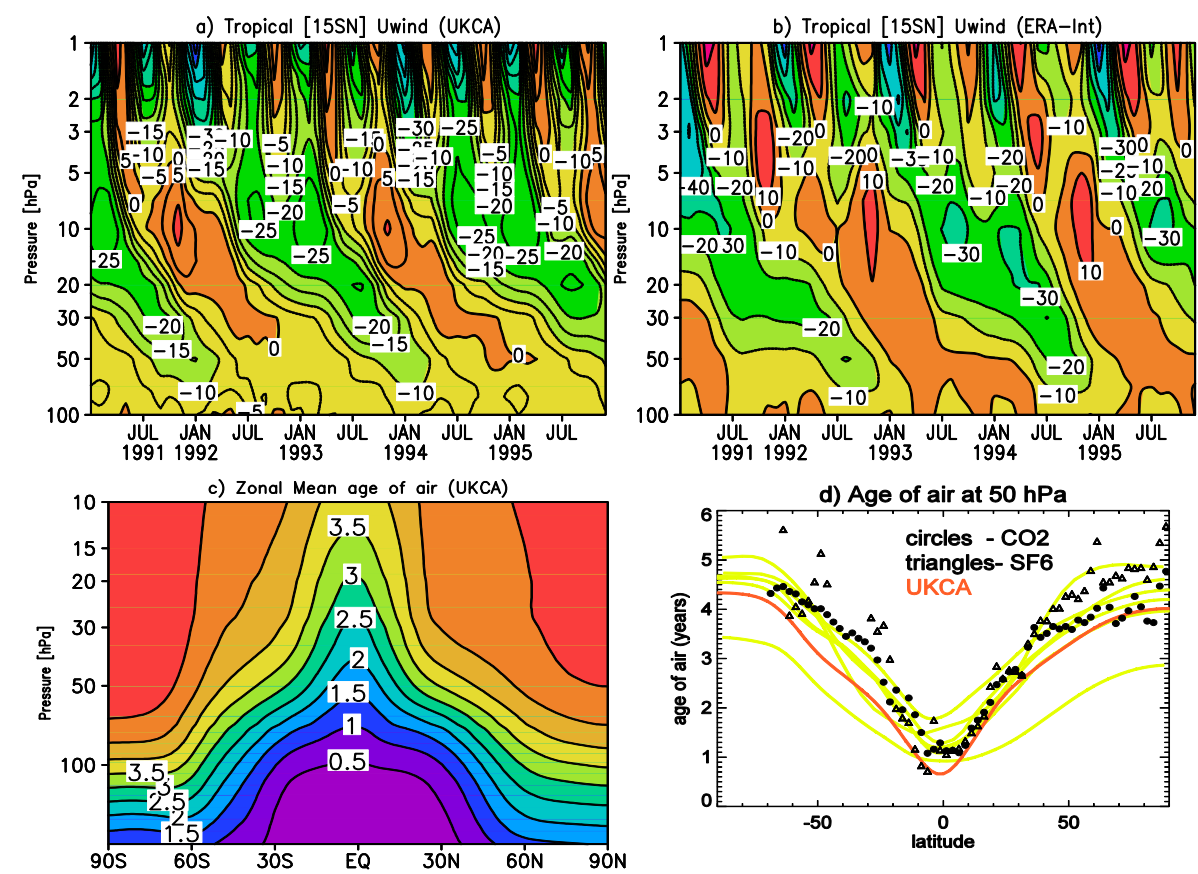

Figure 1. (a) Model-simulated tropical $\left(15^{\circ} \mathrm{S}-15^{\circ} \mathrm{N}\right)$ mean monthly mean zonal wind $\left(\mathrm{m} \mathrm{s}^{-1}\right.$, QBO propagation). (b) Same as (a) but from ERA-interim reanalysis data (Dee et al., 2011). (c) Zonal mean age-of-air (years, mean 1991-2000), and (d) mean age-of-air (1991-2000) comparison at $50 \mathrm{hPa}$. Triangles and filled circles show estimated age-of-air from $\mathrm{CO}_{2}$ and $\mathrm{SF}_{6}$ (Hall et al., 1999). Mean age-of-air from various CCMs which participated in SPARC Lifetime Assessment are shown with yellow lines and the one from this study is shown with the red line.

turn, such a mixing can cause too fast removal of aerosol from the stratosphere into the mid- and high-latitude troposphere, and should be considered when drawing inference from the evaluation of the model post-Pinatubo stratospheric aerosol decay.

\subsection{Global burden and e-folding timescale}

Figure 2 shows the January 1991 to December 1994 time evolution of the daily total global column mass burden of sulfur in the gas phase (as $\mathrm{SO}_{2}$, red) and in the aerosol particle phase (blue) from runs A_Control20 (solid line), B_Control10 (dashed line) and C_noPinatubo (dotted line). Separate lines indicating the upper tropospheric and stratosphere (UTS) aerosol sulfur burden (above $400 \mathrm{hPa}$, green lines) and that in the lower-middle troposphere (below 400 $\mathrm{hPa}$, aqua lines) are also shown. From the no-Pinatubo run C_noPinatubo, the global $\mathrm{SO}_{2}$ and aerosol sulfur burdens are mostly in the troposphere, and their time series are dominated by anthropogenic emission sources, which are mainly in $\mathrm{NH}$ mid-latitudes. Photochemistry is strongest during summer, with higher oxidants then causing efficient conversion of $\mathrm{SO}_{2}$ to aerosol sulfate. Only $10 \%$ of this background total sulfur burden is in the form of $\mathrm{SO}_{2}$ during the $\mathrm{NH}$ summer, compared to around $50 \%$ during winter. We find 30 $40 \%$ of the total aerosol sulfur burden (around $0.5 \mathrm{Tg} \mathrm{S}$ ) is in the stratosphere, which is considerably higher than the $17 \%$

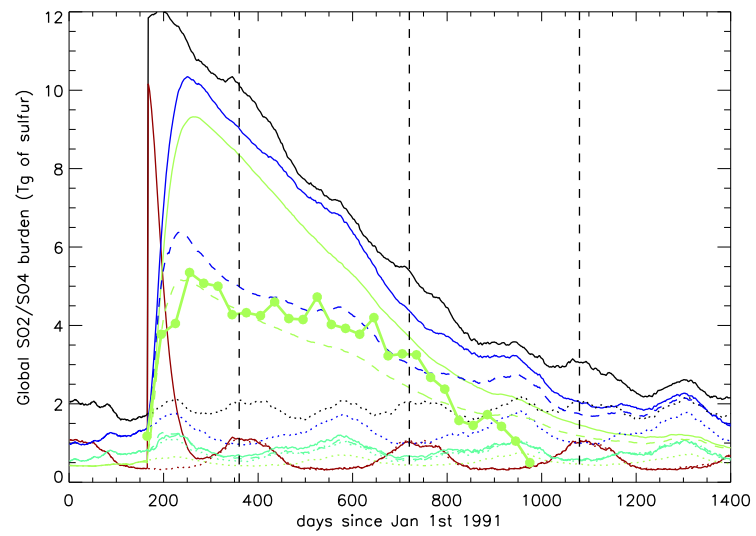

Figure 2. Time series of the global burden (in Tg of sulfur) of $\mathrm{SO}_{2}$ (red), total sulfur (includes both $\mathrm{SO}_{2}$ and aerosol, black), aerosol sulfur (dark blue) for runs A_Control20 (solid lines), B_Control10 (dashed lines), and C_noPinatubo (dotted lines). Integrated aerosol sulfur burdens in the UTS and lower-middle troposphere (determined by above or below $400 \mathrm{hPa}$ ) are also shown with green and aqua lines, respectively. The stratospheric aerosol burden derived by Baran and Foot (1994) using HIRS measurements is shown by the green line with filled circles, assuming $75 \%$ sulphuric acid by weight. 
(0.15 Tg S) found by Hommel et al. (2011). Tropospheric aerosol burdens are also higher than other models (e.g. Textor et al., 2006) at around $1.25 \mathrm{Tg} \mathrm{S}$ on the annual mean.

For run A_Control20, the global column $\mathrm{SO}_{2}$ burden decays from an immediate post-eruption peak of $10.3 \mathrm{Tg}$ to around 2.0, Tg S SO 2 burden on day 226 (60 days after the eruption). Subtracting the $0.3 \mathrm{Tg} \mathrm{SO}_{2}$ mass from B_Control10 (which is all in the troposphere), gives $1.7 \mathrm{Tg} \mathrm{S}$, indicating that 8.3 of the emitted $10 \mathrm{Tg} \mathrm{S}$ emitted as $\mathrm{SO}_{2}$ has been chemically converted to sulfuric acid over that period. We therefore estimate the e-folding timescale for conversion of $\mathrm{SO}_{2}$ into sulfuric acid aerosol as 60 divided by $\ln (10 / 1.7)$ which is 35 days, which agrees closely with most previous studies. For example Bluth et al. (1992) derived an e-folding timescale of 35 days from the TOMS satellite $\mathrm{SO}_{2}$ measurements, but present this as a tentative estimate. McCormick and Veiga (1992) derived an approximate aerosol sulfur burden assuming a $50 \%$ conversion from $\mathrm{SO}_{2}$ to $\mathrm{H}_{2} \mathrm{SO}_{4}$ by the end of July, which corresponds to an e-folding timescale of 43 days. Oman et al. (2006) found an $\mathrm{SO}_{2}$ e-folding conversion timescale of 35 days in their model, which used fixed $\mathrm{OH}$ concentrations. We note however that in the first month of the eruption there is much slower conversion to aerosol of the volcanic emitted $\mathrm{SO}_{2}$, compared to the timescale over 60 days. For example, at day 200 (34 days after the eruption) there is $\sim 5.6 \mathrm{Tg}$ of sulfur in the form of $\mathrm{SO}_{2}$, which gives an e-folding timescale of 59 days. Bekki (1995) found that oxidant concentrations can be strongly depleted after very large volcanic eruptions, and in their Pinatubo simulation Bekki and Pyle (1994), found a timescale of 40 days.

In Fig. 2, we also show a time series of the stratospheric aerosol sulfur burden derived from HIRS measurements by Baran and Foot (1994), assuming a composition of $75 \%$ sulphuric acid by weight. For run A_Control20, we find the peak in UTS aerosol sulfur burden occurs 3 months after the eruption in September, in agreement with the timing derived from HIRS. However, the stratospheric aerosol sulfur burden from A_Control20 is much higher than the observations, with a maximum of $9.3 \mathrm{Tg}$ of sulfur ( $37 \mathrm{Tg}$ aerosol mass assuming $75 \%$ sulfuric acid composition), substantially higher than the $5.4 \mathrm{Tg}$ of sulfur (21.6 Tg of aerosol) from Baran and Foot (1994). Based on ISAMS measurements, Lambert et al. (1993) estimated the post-Pinatubo peak stratospheric aerosol burden as between 19 and $26 \mathrm{Tg}$ ( 4.75 to $6.5 \mathrm{Tg}$ of sulfur). Since A_Control20 gives much too much sulfur in the stratospheric aerosol compared to both of these estimates, we carried out a second control simulation - B_Control10 with $10 \mathrm{Tg}$ of $\mathrm{SO}_{2}$ (dashed line in Fig. 2).

The stratospheric aerosol sulfur burden from B_Control10 is in good agreement with the values derived from HIRS through the second half of 1991 and the whole of 1992. However, the HIRS measurements suggest a return to approximately background stratospheric aerosol levels by the middle of 1993, while the model aerosol shows much slower decay, even showing modest enhancement at the end of 1994.
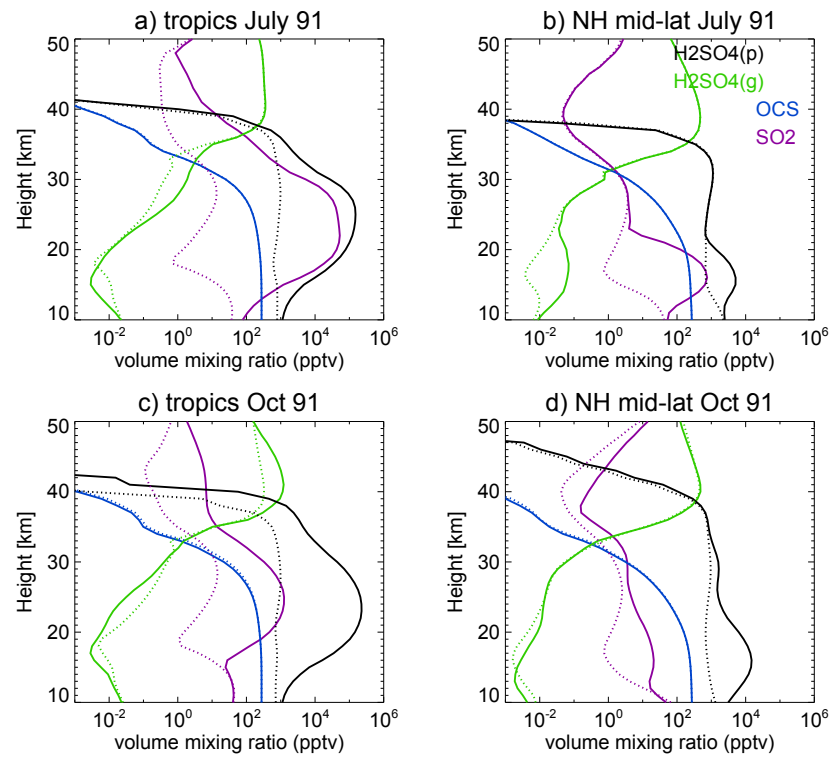

Figure 3. Volume mixing ratios of various sulfur containing species (pptv) in the tropics $\left(20^{\circ} \mathrm{S}-20^{\circ} \mathrm{N}\right.$, left) and $\mathrm{NH}$ mid-latitudes (35$60^{\circ} \mathrm{N}$, right) during July 1991 (top) and October 1991 (bottom). Gas phase and particle phase $\mathrm{H}_{2} \mathrm{SO}_{4}$ ratios are shown with green and black lines, respectively. OCS and $\mathrm{SO}_{2}$ are shown with blue and purple lines, respectively. Runs A_Control20 and C_noPinatubo are shown with solid and dashed lines, respectively.

Also, A_Control20 has a peak stratospheric aerosol burden of $9.3 \mathrm{Tg}$ at about day 260, but the aerosol burden from B_Control10 peaks around a month earlier, at around day 230, with $5.25 \mathrm{Tg}$ of sulfur, which closely matches the HIRS observations. For A_Control20 and B_Control10, we find around $6.1 \mathrm{Tg}$ and $3.5 \mathrm{Tg}$ of sulfur by June 1992 (12 months after the eruption, day 530, day 530, first vertical dashed line in Fig. 2), suggesting e-folding timescales of 19 and 24 months, respectively. The shorter removal timescale for the $20 \mathrm{Tg}$ run is likely due to the particles growing to larger sizes compared to the $10 \mathrm{Tg}$ run (e.g. as seen in Fig. 8), and therefore sedimenting faster, moving to altitudes closer to the tropopause, where removal from the stratosphere is more effective. We note that, despite the close agreement between the A_Control10 and the HIRS-derived burdens, the timescale estimates are considerably longer than values cited in the literature which range from around 12 to 14 months (e.g. see Baran and Foot, 1994 and Bluth et al., 1997).

\subsection{Perturbation in sulfur species}

Figure 3 shows vertical profiles of mixing ratios of the three key gas phase sulfur species OCS, $\mathrm{SO}_{2}, \mathrm{H}_{2} \mathrm{SO}_{4}$, and of sulfuric acid in the particle phase $\left(\mathrm{P}-\mathrm{H}_{2} \mathrm{SO}_{4}\right)$, from runs A_Control20 and C_noPinatubo. The left and right panels are for mean profiles in the tropics $\left(20^{\circ} \mathrm{S}-20^{\circ} \mathrm{N}\right)$ and $\mathrm{NH}$ mid-latitudes $\left(35-60^{\circ} \mathrm{N}\right)$, respectively with the top and bottom rows indicating the means for July 1991 and 
October 1991, selected to correspond to the 15-45 day posteruption period when the $\mathrm{SO}_{2}$ is oxidised to $\mathrm{H}_{2} \mathrm{SO}_{4}$ vapour, and approximately when the peak global aerosol burden occurs in the model. The profile of OCS shows the expected shape, being constant in the troposphere and then reducing with increasing altitude in the stratosphere as it is photolysed. The $\mathrm{SO}_{2}$ profile from run C_noPinatubo shows a sharp reduction with height across the tropopause but then reaches a minimum and begins to increase with height to a local maximum at $30 \mathrm{~km}$ corresponding to where the source from OCS photolysis is largest. Below $30 \mathrm{~km}$ the sulfuric acid vapour follows a similar shape as $\mathrm{SO}_{2}$ (but at lower concentrations) but above that altitude continues to increase up to about $40 \mathrm{~km}$. Below $35 \mathrm{~km}$, the vertical profile of $\mathrm{P}-\mathrm{H}_{2} \mathrm{SO}_{4}$ is approximately constant in the tropics in these quiescent conditions, but has a slight decrease with altitude. In the upper-middle stratosphere rapidly evaporating particles release their $\mathrm{H}_{2} \mathrm{SO}_{4}$ to the gas phase causing a sharp reduction in $\mathrm{P}-\mathrm{H}_{2} \mathrm{SO}_{4}$ about $40 \mathrm{~km}$.

In the tropics, the July profiles from run A_Control20 (Fig. 3a) show large changes in concentrations of $\mathrm{SO}_{2}$ and $\mathrm{P}-$ $\mathrm{H}_{2} \mathrm{SO}_{4}$ (between 20 and $30 \mathrm{~km}$ ) relative to run C_noPinatubo increasing by factors $10^{3}-10^{4}$ and factor $10^{2}$, respectively. The enhanced $\mathrm{P}-\mathrm{H}_{2} \mathrm{SO}_{4}$ profile indicates that much of the $\mathrm{SO}_{2}$ has already been oxidised and condensed into the particle phase. By contrast, the NH mid-latitude July profiles show that the Pinatubo plume has not yet been transported, with $\mathrm{SO}_{2}$ and aerosol $\mathrm{H}_{2} \mathrm{SO}_{4}$ still at quiescent concentrations over almost the entire stratosphere, although some perturbation can be observed in the lowermost stratosphere and uppermost troposphere. It is notable that balloon-borne particle concentration soundings at Laramie $\left(41^{\circ} \mathrm{N}\right)$ in July 1991 already show some enhanced layers between 15-18 km (Deshler et al., 1992) which corresponds well with the altitude of the $\mathrm{SO}_{2}$ and $\mathrm{P}-\mathrm{H}_{2} \mathrm{SO}_{4}$ enhancement seen in the July-mean $\mathrm{NH}$ mid-latitude profiles.

The October mean $\mathrm{SO}_{2}$ profile is still strongly enhanced (factor 100) in the tropics with the $\mathrm{P}-\mathrm{H}_{2} \mathrm{SO}_{4}$ enhancement only slightly higher than in July but over a much deeper layer. This tropical enhancement in both $\mathrm{SO}_{2}$ and $\mathrm{P}-\mathrm{H}_{2} \mathrm{SO}_{4}$ propagates up to about $40 \mathrm{~km}$, and above that only the $\mathrm{SO}_{2}$ profiles show differences between runs A_Control20 and C_noPinatubo. It is interesting that the October 1991 tropical gas phase $\mathrm{H}_{2} \mathrm{SO}_{4}$ profile from run A_Control20 actually shows lower values than in run C_noPinatubo in the main part of the plume $(15-30 \mathrm{~km})$, due to the condensation sink to aerosol being so much stronger. By contrast, above $30 \mathrm{~km}$ the increase in vapour pressure shuts off the condensation sink leading to the $\mathrm{H}_{2} \mathrm{SO}_{4}$ vapour concentrations being higher than quiescent at those altitudes. The October $1991 \mathrm{NH}$ midlatitude $\mathrm{SO}_{2}$ and $\mathrm{P}-\mathrm{H}_{2} \mathrm{SO}_{4}$ profiles show only moderate enhancement, suggesting that the easterly phase of the QBO has prevented transport of Pinatubo-enhanced air masses.

\subsection{Stratospheric aerosol optical depth (sAOD) comparison}

Figures $4 \mathrm{a}$ and $\mathrm{b}$ show the time evolution of the model mid-visible sAOD from runs A_Control20 and B_Control10 while Fig. $4 \mathrm{c}$ and $\mathrm{d}$ show the mid-visible sAOD measured by SAGE II and derived from AVHRR. Since AVHRR is a nadir viewing instrument, in Fig. 4d we have subtracted monthly-mean total AODs for the year prior to the eruption, matching the procedure recommended by Long and Stowe (1994) and used by Aquila et al. (2012). Note that the SAGEII-derived sAOD is much lower than AVHRR in the tropics during the very high loading period after Pinatubo due to the measured extinction saturating at values above about $0.01 \mathrm{~km}^{-1}$ (Hamill et al., 2006). In both the A_Control20 and B_Control10 runs there is good qualitative agreement with the satellite regarding spatial and temporal distribution. For example, there is high sAOD after the eruption centred around the equator with peak sAOD in September 1991 in both model simulations and in the two satellite data sets. However, the model feature is narrower, confined between $10^{\circ} \mathrm{N}$ and $10^{\circ} \mathrm{S}$. Another well-captured feature in the model is that there is no significant enhancement of sAOD in $\mathrm{NH}$ mid- and high latitudes until October 1991.

However, consistent with Fig. 2 (more aerosol loading than estimated by Baran and Foot, 1994) the simulated sAOD in A_Control20 is much larger than both sets of observations. The sAOD distribution in B_Control10 is in better agreement with the satellite measurements, comparing well to both satellite measurements in mid- and high latitudes. Comparing to the observed sAOD enhancements in the SH, both model simulations are also in quite good qualitative agreement. However, in the tropics the sAOD in B_Control10 is still about $50 \%$ larger than that derived from AVHRR, and a factor of 2 larger than SAGE II. Possible causes for these biases are discussed later in this section.

\subsection{Extinction comparison}

Extinction profile measurements from SAGE II between July and September show (e.g. McCormick et al., 1995) that transport to the SH occurred mostly above about $24 \mathrm{~km}$ altitude. Aquila et al. (2012) highlighted the importance of resolving the enhanced tropical upwelling which occurred due to the long-wave absorption by the relatively larger stratospheric aerosol after the Pinatubo eruption. As explained in Sect. 2, in these simulations we do not radiatively couple the simulated aerosol with the model dynamics, and yet we capture quite well the $\mathrm{SH}$ post-Pinatubo sAOD evolution. We note that Aquila et al. (2012) do not include evaporation of sulfuric acid in their model, which could play an important role in influencing transport to SH mid-latitudes.

Figure 5 shows a time series of aerosol extinction from the three model simulations (runs A_Control20, B_Control10, C_noPinatubo) and SAGE II at 32,25 and $20 \mathrm{~km}$ in the 

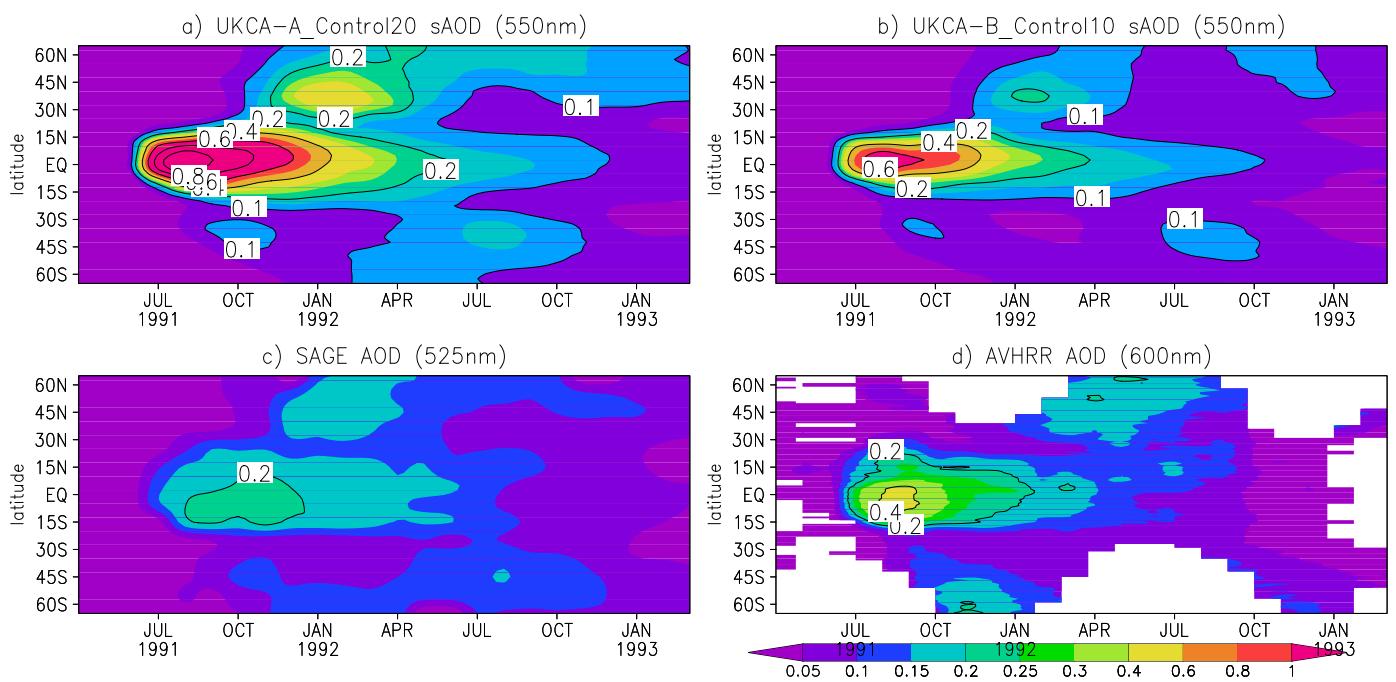

Figure 4. Time series of model-simulated zonal mean sAOD at $525 \mathrm{~nm}$ (calculated by integrating the extinction above the tropopause) for runs (a) A_Control20 and (b) B_Control10. (c) and (d) show the sAOD measured by SAGE II (525 nm) and derived from AVHRR (600 nm) measurements. AVHRR sAOD is derived as the difference from the background total AOD from the 2 years before the eruption (Long and Stowe, 1994).

tropics $\left(20^{\circ} \mathrm{S}-20^{\circ} \mathrm{N}\right)$. We choose these altitudes to allow comparison with the evaluation presented in Weisenstein et al. (2006, Fig. 6.20) for other stratospheric aerosol models. We compare extinction in the mid-visible (left panels) as well as the near-infrared (right panels). Here we use the updated v7.0 SAGE II data set and the profiles shown are averages between $20^{\circ} \mathrm{S}$ and $20^{\circ} \mathrm{N}$. Monthly mean observed values are calculated based on both sunrise and sunset profiles.

At 20 and $25 \mathrm{~km}$, both runs (A_Control20 and B_Control10) capture the general evolution of the tropical mid-visible extinction (Fig. 5), with the magnitude and timing of peak values, and the decay timescale, agreeing well with SAGE II. However, before the eruption (background conditions), modelled extinctions have a moderate low bias of $20-50 \%$ at these levels. For the tropical mid-visible extinction time series, run B_Control10 is in better agreement with the observations than A_Control20, which tends to be high biased (consistent with the SAOD and aerosol mass high biases seen in Figs. 2 and 4 respectively). However, against the tropical near-infrared extinction, run A_Control20 is in better agreement, with run B_Control10 generally showing modest low bias, although still in reasonable agreement. At $25 \mathrm{~km}$, and for both wavelengths, the model tropical extinction peaks in August 1991, whereas in the satellite measurements, values plateau for $2-3$ months before the decay period begins. In the model, the decay is fastest in the first 6-8 months after the peak value, with an approximately constant e-folding timescale from mid-1992 onwards. The faster decay in the early phase may be due to the shift in size distribution which produced larger particles at this time. Faster sedimentation would remove larger particles during this initial period, with the remaining (smaller on average) particles sedimenting more slowly. Larger model high bias is seen for simulated tropical extinctions at $32 \mathrm{~km}$, for both the runs (A_Control20 and B_Control10) that may indicate that the upper altitude used for $\mathrm{SO}_{2}$ injection was too high. At $32 \mathrm{~km}$, the modelled extinction is slightly larger than SAGE II and, although peaks and troughs are mostly similar to the satellite measurements, the model variability is less than in the observations. We note again that the simulations presented here do not include the dynamical effects of aerosol-induced radiative heating. Such a radiative heating is known to cause increased tropical upwelling, which would cause greater dilution, could alter horizontal transport through the subtropical barrier and may also alter microphysical processes such as evaporation and coagulation.

Figure 6 shows a similar analysis to Fig. 5, but for $\mathrm{NH}$ mid-latitudes $\left(35-60^{\circ} \mathrm{N}\right)$, again to compare against models shown in Weisenstein et al. (2006). At $20 \mathrm{~km}$, there is very good agreement between modelled and SAGE II extinctions at both mid-visible and near-infrared wavelengths. Similarly good agreement is also observed at $25 \mathrm{~km}$. However, during 1993, SAGE II measurements show a significant decrease at both wavelengths which is not captured by the model. At $32 \mathrm{~km}$ the modelled extinction enhancement is slightly larger than the observations. We also note that whereas in the tropics the model and observations showed a faster decay phase in the first 6-8 months after the peak aerosol loading compared to the later phase, in $\mathrm{NH}$ midlatitudes, both model and observations have constant exponential decay timescale throughout the post-eruption period. For this latitude band, the model shows much better agreement with SAGE II measurements than seen in any of 

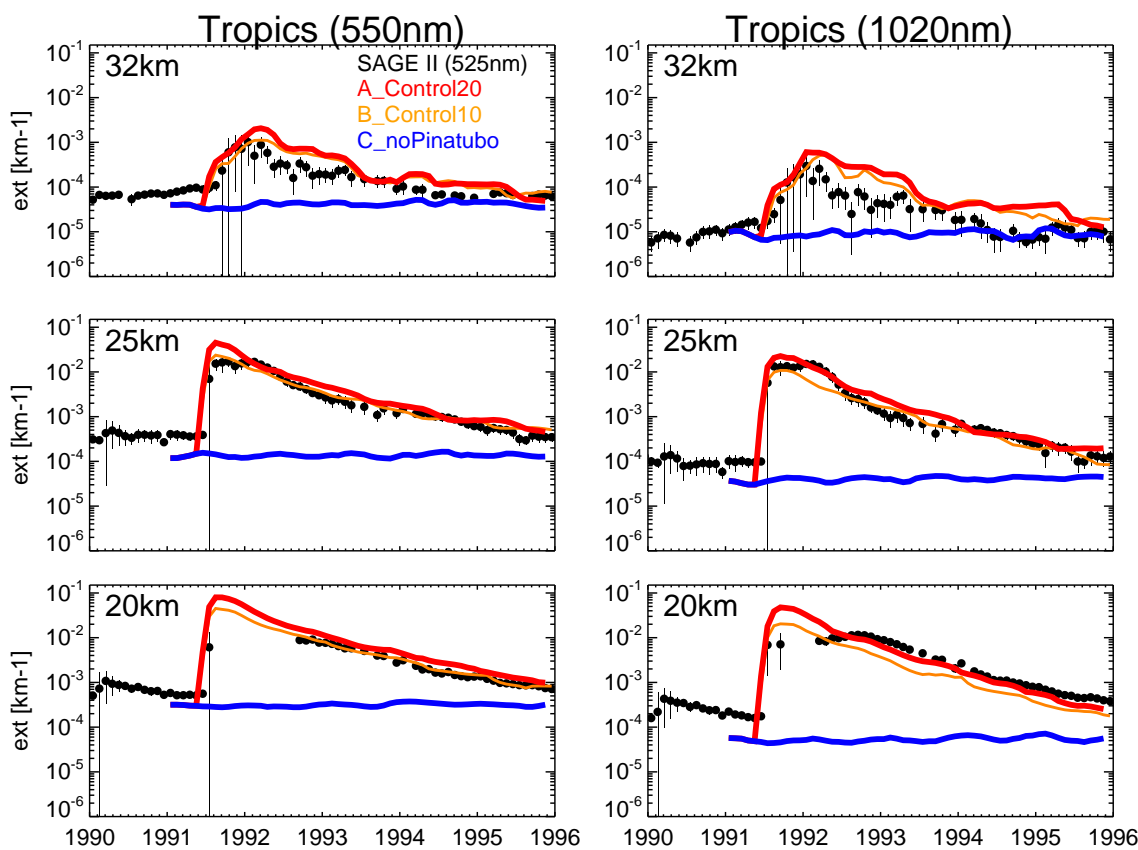

Figure 5. Comparison between modelled and SAGE II (V7.0) retrieved extinction at $525 \mathrm{~nm}$ (left) and $1020 \mathrm{~nm}$ (right) in the tropics (20 $0^{\circ}$ $20^{\circ} \mathrm{N}$ ) for $20 \mathrm{~km}$ (bottom), $25 \mathrm{~km}$ (middle) and $32 \mathrm{~km}$ (top). Extinctions from runs A_Control20, B_Control10 and C_noPinatubo are shown with red, orange and blue lines, respectively. The vertical black lines show the range of plus or minus one standard deviation over the individual measurements used in the calculation of the monthly mean.
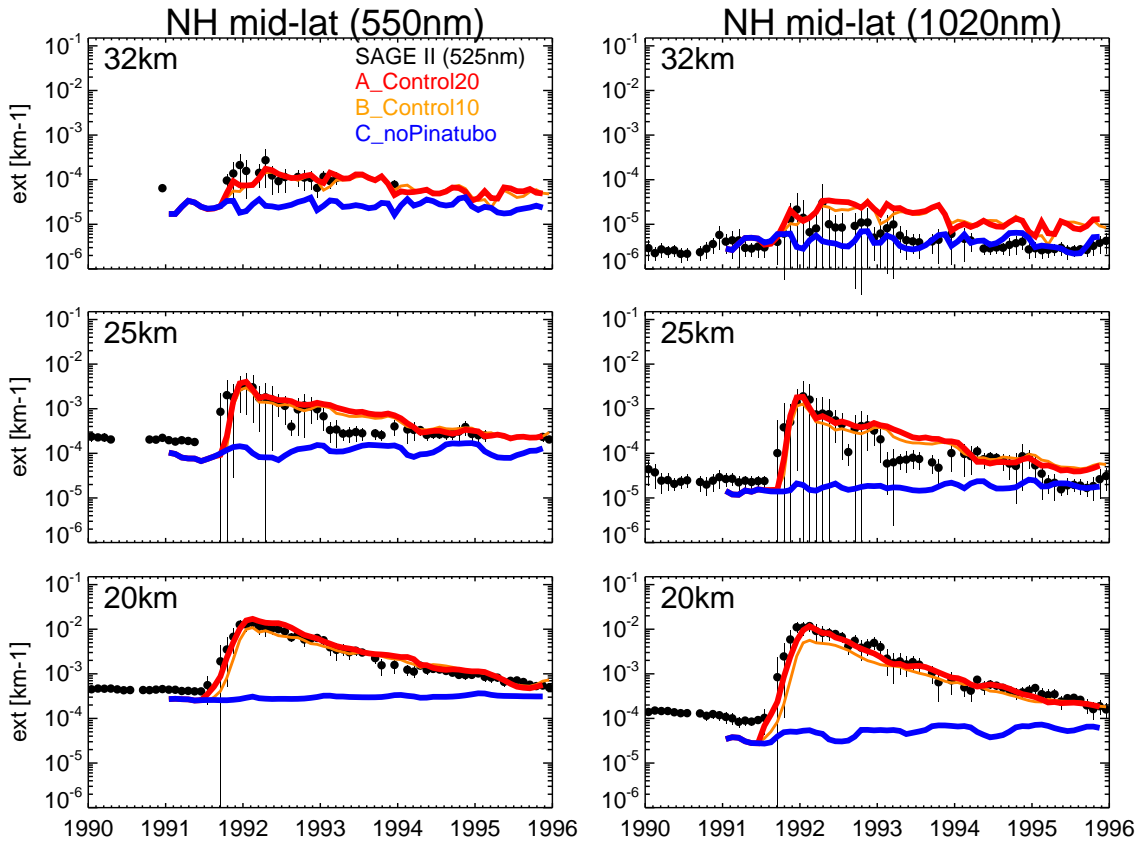

Figure 6. Same as Fig. 5 but for $\mathrm{NH}$ mid-latitudes $\left(35-65^{\circ} \mathrm{N}\right)$.

the simulations submitted for the Pinatubo intercomparison in SPARC (2006). Interestingly, differences between runs A_Control20 and B_Control10 are much smaller at this latitude band than in the tropics (Fig. 5), suggesting a larger pro- portion of aerosol is removed in the tropics in the $20 \mathrm{Tg}$ run than in $10 \mathrm{Tg}$ run (likely related to stronger sedimentation). As we also saw in the tropics, in the NH mid-latitudes, at 

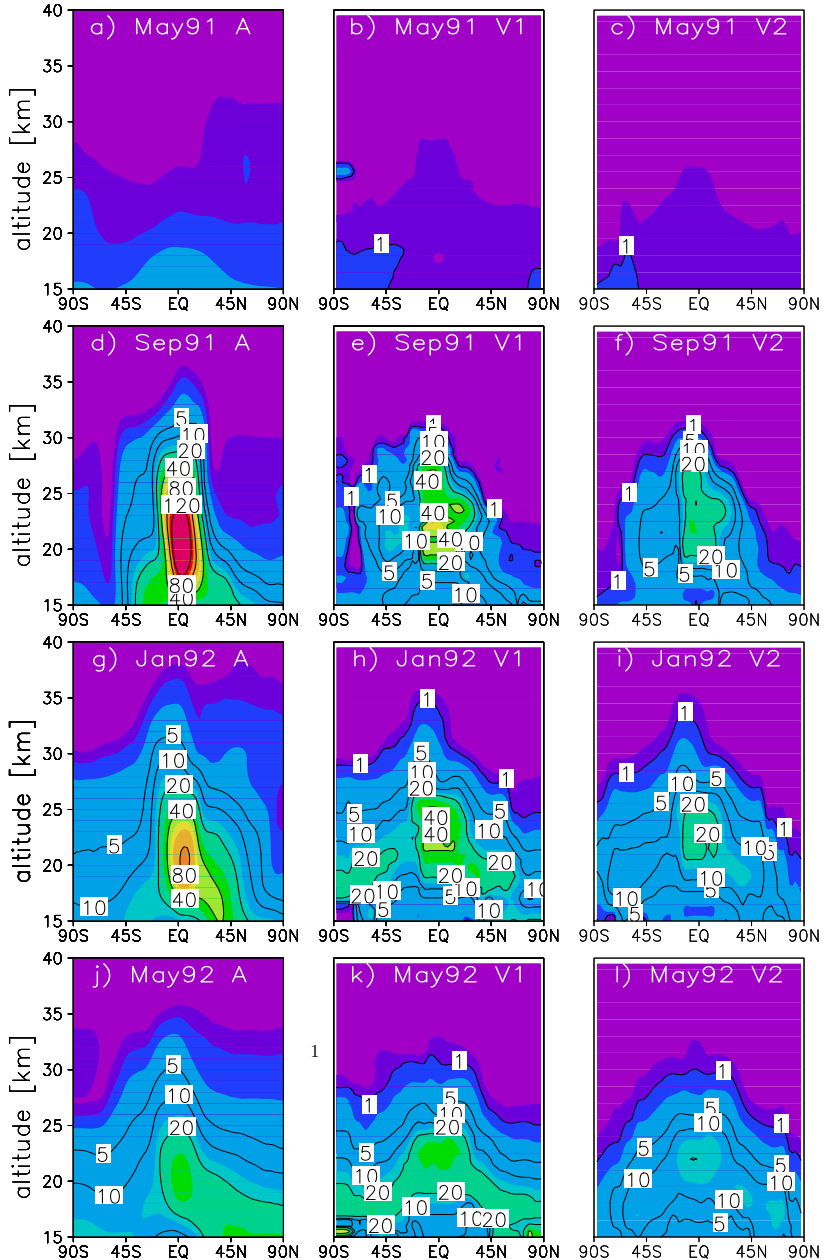

Figure 7. Comparison between zonal mean modelled (run A_Control20) and satellite-derived V1 and V2 SAD $\left(\mu \mathrm{m}^{2} \mathrm{~cm}^{-3}\right)$ from SPARC (2006) and Arfeuille et al. (2013), respectively, for various months before and after the eruption.

$20 \mathrm{~km}$, the $1020 \mathrm{~nm}$ extinction from run A_Control20 shows better agreement with SAGE II than B_Control10.

\subsection{Surface area density comparison}

Figure 7 compares the vertical and latitudinal distribution of zonal mean SAD from run A_Control20 against two versions of the satellite-derived SAD data set, for 4 selected months between May 1991 and May 1992. Before the eruption (May 1991), the model captures the global SAD distribution reasonably well compared to the SAGE-derived data sets, although model values are higher in the upper troposphere and lower stratosphere (UTLS) region. For September 1991 (3 months after the eruption), although the simulated SAD distribution broadly matches the observed shape, it is up to a factor 2 to 3 high in the tropics. Also, the model Pinatubo-enhanced SAD plume is strongly confined to the tropical pipe, whereas in the satellite-derived SAD (Fig. 7d) one can see weak meridional transport to $\mathrm{NH}$ and $\mathrm{SH}$ subtropics at about 20-22 km. Young et al. (1994) showed that including the aerosol radiative effects on the model dynamics broadens the latitudinal extent of the Pinatubo cloud which, in our simulations would improve agreement with the satellite observations. And as mentioned earlier, such a heating can alter local circulation and may partially explain the SAD high biases seen here. By January 1992, the model high bias has reduced to a factor of 2 , and the model shows meridional transport to $\mathrm{NH}$ mid-latitudes in the lowermost stratosphere, also seen in the observations. However, the satellite-derived SAD suggests meridional transport also occurs to the $\mathrm{SH}$, but at slightly higher altitudes. By May 1992, high biases in modelled SAD are much smaller and the general latitudinal and altitudinal distribution is still in good qualitative agreement with the observations, aside from the continued low bias in the SH. Also, as observed in Fig. 2 (younger ageof-air), in the lowermost stratosphere, the model seems to have too much diffusion near the tropopause. Hence the distinct cross-tropopause gradients seen in satellite data are not seen in our simulations.

While interpreting the model-observation SAD discrepancies, one should consider how the satellite SAD product is derived from the SAGE I, SAGE II, SAM II (Stratospheric Aerosol Instrument II) and SME (Solar Mesosphere Explorer) measurements. As noted earlier, the extinction measured by the SAGE and SAM instruments has an upper limit of $0.01 \mathrm{~km}^{-1}$, above which the atmosphere is effectively opaque to the instruments (Hamill et al., 2006). During the peak aerosol loading period, when the model SAD is a factor of 2 high biased, it is apparent (for example in Fig. 5) that the SAGE II $525 \mathrm{~nm}$ and $1020 \mathrm{~nm}$ extinctions in the tropical lower stratosphere are saturating at the upper limit value, with actual extinction values likely to have been higher. The late-1991 to 1992 period was flagged as missing data in the original SAGE II extinction data set. The data gaps during that period were addressed by Hamill et al. (2006), who used lidar data from two tropical sites (Camaguey, Cuba and Mauna Loa, Hawaii) and two mid-latitude sites (lidar from NASA Langley, Virginia, USA and backscatter sonde from Lauder, New Zealand), to fill the missing data.

Another important issue to consider with the SAGE-IIderived SAD product is that, even outside the gap-filled part of the data set, particles smaller than $50 \mathrm{~nm}$ are essentially invisible to the satellite and there is little sensitivity to particles smaller than $100 \mathrm{~nm}$. For example, Reeves et al. (2008) derived extinction, SAD and volume concentration from aircraft measurements of the aerosol particle size distribution (in quiescent conditions) and compared to SAGE II products. They found that the aircraft measured SAD was a factor 1.5-3 higher than the SAGE-II-derived values, whereas volume concentrations were only $35 \%$ higher.The apparent SAD high bias in the model may therefore partly be caused by the contribution from smaller particles which are not observable from the SAGE II instrument 


\subsection{Effective radius comparison}

Another product derived from the gap-filled satellite extinction record, that can be used to assess the evolution of the stratospheric aerosol properties following the Pinatubo eruption, is $R_{\text {eff }}$, defined as the ratio of the third and second integral moments in radius, and which for multimodal distribution can be represented as (Russell et al., 1996, Eq. 6)

$R_{\mathrm{eff}}=\frac{\sum_{i=1}^{m} N_{i} r_{g i}^{3} \exp \left[9 / 2\left(\ln \sigma_{i}\right)^{2}\right]}{\sum_{i=1}^{m} N_{i} r_{g i}^{2} \exp \left[2\left(\ln \sigma_{i}\right)^{2}\right]}$.

The two gap-filled SAGE/SAM extinction data products provide 3-D time-varying volume concentration and SAD which together give $R_{\text {eff }}$ throughout the Pinatubo period. This record therefore has the potential to provide information on how the particle size distribution in the stratosphere was perturbed by the eruption. However, again, when comparing the model to the satellite $R_{\text {eff }}$, the limitations associated with the derived product need to be considered. In particular, because of the "blind spot" associated with particles smaller than 50-100 nm, Hamill et al. (2006) state that since the derived SAD may have an inherent low bias (whereas the derived volume density will be less affected) the derived $R_{\text {eff }}$ may overestimate the true value.

Figure 8 shows the evolution of the model zonal-mean $R_{\text {eff }}$ at 20 and $25 \mathrm{~km}$ from runs A_Control20 and B_Control10 compared to that derived by Bauman et al. (2003) from the SAGE II and CLAES satellite measurements. The general spatial and temporal evolution of the model $R_{\text {eff }}$ is in good qualitative agreement with the observations in both runs, with values at $20 \mathrm{~km}$ larger than at $25 \mathrm{~km}$, likely due to sedimentation. In the tropics, at both altitudes, the observations suggest that, whereas SAOD and extinction are decaying by November or December 1991 (Figs. 4 and 5), the effective radius peaks several months later (early 1992) with only a slow decay beginning later in 1992. By contrast, in NH mid-latitudes, the observations suggest that the decay in effective radius is slightly earlier and occurs faster. Both simulations capture the timing of these $R_{\text {eff }}$ peaks well, although at $25 \mathrm{~km}$, the model peak is later than observed, matching the timing at $20 \mathrm{~km}$. Effective radius values are always higher in the tropics than at mid-latitudes, a feature that is consistent between the model and observations. However, although $R_{\text {eff }}$ from run A_Control20 is slightly larger than from B_Control10, modelled values are up to 30-40\% smaller than those derived from the satellite, with maximum model $R_{\text {eff }}$ of around 0.4 and $0.35 \mu \mathrm{m}$, compared to around $0.6 \mu \mathrm{m}$ from the satellites.

At $20 \mathrm{~km}$ (Fig. 8b), despite combining the two sets of satellite products, there is no observational constraint on the tropical $R_{\text {eff }}$ between approximately June 1991 and August 1992, but the overall shape suggests the $R_{\text {eff }}$ was likely even larger than $0.6 \mu \mathrm{m}$ during that period. The model low bias in $R_{\text {eff }}$ is apparent at about the same extent at all latitudes and alti- tudes and before the eruption, which suggests that it is not associated with sedimentation, since that would be expected to occur mostly during the highest loading period. There appears to be a more persistent bias in simulated particle size distribution, but it is unclear whether the model has too many small particles, or too few large particles.

\subsection{Particle size distribution}

To give a stronger observational constraint on the simulated size distribution, we compare the model against balloonborne $\mathrm{CNC}$ and $\mathrm{OPC}$ measurements made at Laramie, Wyoming, USA $\left(41^{\circ} \mathrm{N}\right.$, see Sect. 3). Figures 9 and $10 \mathrm{com}-$ pare model profiles of size-resolved number concentrations (larger than a given particle diameter) against those measured by the CNC and OPC. In each case we are comparing a monthly-mean size-resolved particle concentration from the model to a single balloon sounding. Note also that whereas the number concentration profiles for particles larger than $5 \mathrm{~nm}, 150 \mathrm{~nm}$ and $250 \mathrm{~nm}$ are exactly as measured by the OPC, for the larger size channels we have interpolated the observations (linearly in $\log N$ vs. $\log R$ space) onto regular $D_{\mathrm{p}}>550 \mathrm{~nm}, 750 \mathrm{~nm}$ and $1000 \mathrm{~nm}$ size channels from the irregular size thresholds given in the individual sounding data files.

Figure 9 shows the observed (plus signs) profile evolution of the particle size distribution through August to November 1991, for the period after the Pinatubo plume was first detected at Laramie on 16 July (Deshler et al., 1992). In August and September 1991, both runs A_Control20 and B_Control10 show elevated values of $N_{150}$ and $N_{250}$ between 14 and $20 \mathrm{~km}$, whereas at higher altitudes (above 25 $\mathrm{km}$ ) the profile remains close to background values (not shown). The region with elevated $N_{150}$ and $N_{250}$ profiles matches reasonably well with the observations, and indicates efficient transport of air from the tropics in the lowermost stratosphere. However, above $25 \mathrm{~km}$ the model is not able to simulate steeper decreases observed in vertical profiles of $N_{150}$ and $N_{250}$. Intriguingly, in November 1991 (Fig. 9d) run A_Control20 predicts only slightly higher $N_{150}$ and $N_{250}$ than run B_Control10, with particle concentrations at larger sizes showing a much larger relative enhancement in the $20 \mathrm{Tg}$ run than the $10 \mathrm{Tg}$ run. The size distribution simulated by the model is generally in good agreement with the observations, although in August and September 1991, for the peak at about $18 \mathrm{~km}$, the model $N_{550}$ are low biased compared to the observations, and there is a general overprediction of $N_{5}$ in this initial post-eruption phase. The low bias in the larger sizes could be related to the high bias in the smallest sizes, with the condensation sink being shared out across a larger number of particles leading to reduced particle growth. Another possibility is that there is faster STE as observed in the age-of-air comparison (Fig. 1c and d). Observations also show approximately constant $N_{5}$ between 20 and $30 \mathrm{~km}$, but run A_Control20 (B_Control10) have elevated 

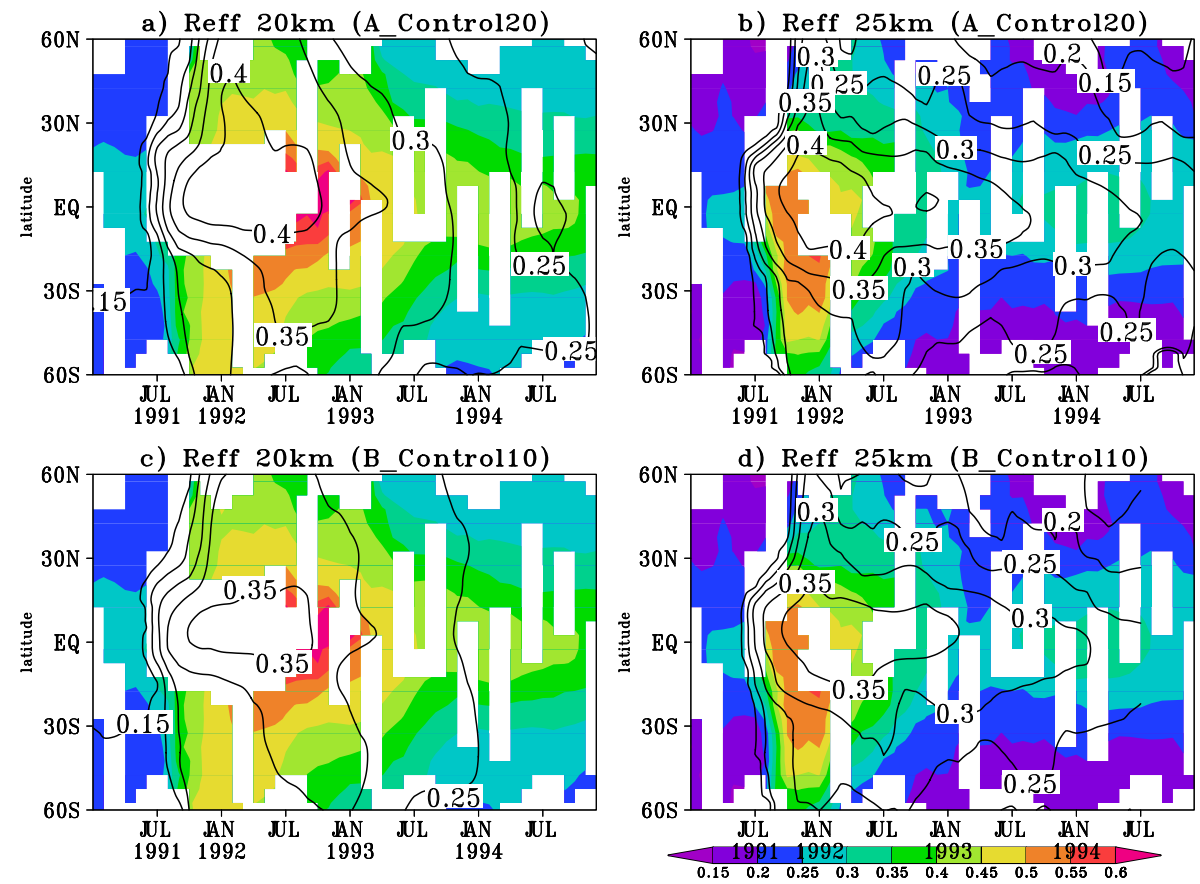

Figure 8. Satellite-derived (shaded, from Bauman et al., 2003) and modelled (contours) effective radii $\left(R_{\text {eff }}\right)$ in $\mu \mathrm{m}$ at 25 and $20 \mathrm{~km}$ from runs A_Control20 (panels a and b) and B_Control10 (panels c and d).

$N_{5}$ between 20 and $25 \mathrm{~km}$. The observations show that concentrations of particles at $150 \mathrm{~nm}$ and larger reduce sharply above $25 \mathrm{~km}$, whereas the model profiles show only moderate decline. This suggests that the simple approach to particle evaporation may need improving.

For November 1991, the run A_Control20 shows enhancement up to $25 \mathrm{~km}$ for all the particle size thresholds, with the coarse mode higher than the run C_noPinatubo in the lowermost stratosphere (not shown) and the shape of the vertical profile for each channel compares well with the observations. The model also shows an enhanced layer of $N_{5}$, $N_{150}$ and $N_{250}$ at about $35 \mathrm{~km}$, suggesting transport of the Pinatubo plume to mid-latitudes throughout the lower and middle stratosphere. In both the model and observations, in these initial months, there is a layer where the $N_{5}$ and $N_{150}$ lines come together, reflecting that few particles remain smaller than $150 \mathrm{~nm}$ and indicating that particle growth at these sizes is strongest in that part of the stratosphere. We note however that in the observations this confluence occurs at around $20 \mathrm{~km}$, whereas in the model this occurs around $16-17 \mathrm{~km}$. This discrepancy in altitude could be reflecting the chosen injection height range, or be related to transport deficiencies in the model, and the general good qualitative agreement with the observations suggests that the modal approach to aerosol dynamics is capturing the evolution of the size distribution rather well.

In order to evaluate the model size distribution profile in quiescent conditions, we compare to the Laramie balloon measurements in March 1991 (Fig. 10a). We then probe the longer-timescale evolution of the size distribution through the Pinatubo period, comparing soundings in March 1992, 1993 and 1994 (Fig. 10b, c and d). Before the eruption, the observations show that $N_{5}$ decreases with increasing altitude between 12 and $23 \mathrm{~km}$, whereas $N_{150}$ and $N_{250}$ show a much slower decrease with height. This feature is well captured by the model with $N_{5}$ and $N_{150}$, in excellent agreement with the observations in this altitude range, although $N_{250}$ has a slight low bias. Between 25 and $30 \mathrm{~km}$, the observed $N_{5}$ profile shows a layer of enhanced concentrations, by around a factor of 10 compared to a continuation of the decrease seen at lower altitudes. This layer indicates a source of freshly nucleated particles which have not grown to larger sizes. The simulated $N_{5}$ profile also shows this feature, but the enhancement of particle concentrations is much stronger in the model, and extends to lower altitudes, down to around $20 \mathrm{~km}$. Gas phase sulfuric acid concentrations are known to increase rapidly with height in this region from balloon-borne ion mass spectrometer measurements (e.g. Arnold et al., 1981). These elevated concentrations of gas phase $\mathrm{H}_{2} \mathrm{SO}_{4}$ have been shown to cause significant nucleation in the middle stratosphere (Hommel et al., 2011) which is almost certainly the cause of this feature. The high bias in the model $N_{5}$ profile in this enhanced layer likely indicates that nucleation is too strong in the model. The overpredicted nucleation rate in these volcanically quiescent conditions may be a result of gas phase concentrations of $\mathrm{H}_{2} \mathrm{SO}_{4}$ being too high in the model. Possible explanations might be that the model does not include the sink for gas phase $\mathrm{H}_{2} \mathrm{SO}_{4}$ provided by meteoric debris, 
shown to be important by Saunders et al. (2012) and Brühl et al. (2013) or underestimated $\mathrm{H}_{2} \mathrm{SO}_{4}$ photolysis rates in our simulations.

In March 1992 (Fig. 10b), 9 months after the eruption, the observed particle concentration profiles show major enhancements throughout the upper troposphere and lower stratosphere (10 to $25 \mathrm{~km}$ ), for size channels $150 \mathrm{~nm}$ and larger. By contrast, $N_{5}$ shows a slight decrease compared to March 1991, and is only marginally higher than $N_{150}$ and $N_{250}$ for this month, suggesting that a large proportion of the particles have grown to sizes larger than $250 \mathrm{~nm}$. The enhanced profiles of $N_{550}, N_{750}$ and $N_{1000}$ are approximately constant between 15 and $20 \mathrm{~km}$ with a fast decrease at higher altitudes. Model run A_Control20 (solid line) captures this volcanically enhanced particle size distribution remarkably well, with good qualitative and quantitative agreement across all the size channels in the main part of the plume. Run B_Control10 (dashed line) also captures well the $N_{5}, N_{150}$ and $N_{250}$ profiles, but is low biased in the larger size channels. Despite generally very good agreement with the Laramie OPC data at this time, in the lowermost stratosphere and upper troposphere (between 10 and $15 \mathrm{~km}$ ), both model runs show a high bias in $N_{150}$ and $N_{250}$. We saw from the previous comparisons that run A_Control20 has too high a burden in the stratospheric aerosol compared to the HIRS and ISAMS satellite measurements (Fig. 2) and that it is strongly biased high in aerosol optical depth against the SAGE II and AVHRR data (Fig. 4). The comparisons to the OPC data suggest that the high sAOD bias originates from the overpredicted particle concentrations in the 150 to $550 \mathrm{~nm}$ radius range in the lowermost stratosphere, with coarser particles in that part of the atmosphere in reasonable agreement (run A_Control20) or showing low bias (run B_Control10).

In March 1993 (Fig. 10c), the observations show clear separation between $N_{5}$ and $N_{150}$, although $N_{150}$ and $N_{250}$ are close together. This indicates the formation of a bimodal size distribution consisting of an external mixture of particles which have grown to larger sizes following condensation after oxidation of volcanic $\mathrm{SO}_{2}$ and a separate sub-population of particles less influenced by the eruption. Observed profiles of $N_{550}, N_{750}$ and $N_{1000}$ show peak values at around $12 \mathrm{~km}$ at this time, much lower altitudes than at March 1992 (Fig. 10b). It is interesting that the March $1993 N_{550}$ and $N_{750}$ profiles are higher in the $10-15 \mathrm{~km}$ region than in March 1992, likely indicating that, although slow at these particle sizes, sedimentation is transporting the particles to lower altitudes over these longer timescales. The model captures the observed size distribution fairly well, with $N_{250}$ in quite good agreement with the measurements. However, the model $N_{150}$ profile has a high bias of around a factor of 2 during March 1993 and is still together with the $N_{5}$ profile between 15 and $20 \mathrm{~km}$. Also, simulated particle concentrations in the larger size channels have a strong low bias of around a factor of 10 (run A_Control20) or 20 (run B_Control10) in the lowermost stratosphere at this time, with the simu- lated profiles not capturing the increase in particles larger than $N_{550}$ in the lowermost stratosphere. By March 1994 (Fig. 10d) the OPC measurements show that there has been a general decay in all size channels towards background conditions. The model $N_{150}$ high bias seen in March 1993 has worsened with the decay rate at these channels slower than in the observations. In the $N_{550}, N_{750}$ and $N_{1000}$ channels, the model continues to have a low bias in both simulations. It is notable that throughout the period, the model $N_{150}$ and $N_{250}$ profiles are remarkably similar between the A_Control20 and B_Control10 simulations, with much larger differences in the coarser sized particles.

\section{Discussion}

In Sect. 4.2 we found that injecting $20 \mathrm{Tg} \mathrm{SO} \mathrm{S}_{2}$ into the tropical stratosphere substantially overestimates the stratospheric aerosol sulfur burden, with a $10 \mathrm{Tg} \mathrm{\textrm {SO } _ { 2 }}$ injection in much better agreement with observations. Most previous modelling studies of the Pinatubo eruption have also tended to inject $20 \mathrm{Tg}$ of $\mathrm{SO}_{2}$, and we show here that the high bias in our model is also found in other studies. Oman et al. (2006) and English et al. (2013) found peak stratospheric sulfuric acid aerosol burdens of 27 and $24 \mathrm{Tg}$ respectively, translating to 36 and $32 \mathrm{Tg}$ aerosol mass assuming $75 \%$ weight sulfuric acid, similar to our $37 \mathrm{Tg}$ peak value. Niemeier et al. (2009) injected $17 \mathrm{Tg}$ of $\mathrm{SO}_{2}$, and their $30 \mathrm{Tg}$ peak stratospheric aerosol burden also agrees with our simulation, accounting proportionally for the reduced sulfur source. We note also that Niemeier et al. (2009) and English et al. (2013) have presented the HIRS stratospheric aerosol burden time series from Baran and Foot (1994) assuming the mass burden is for sulfuric acid, without accounting for the fraction of water content implicit in those values.

For our $10 \mathrm{Tg}$ Pinatubo simulation, we found generally good agreement with observed sAOD (section 4.4), extinction (section 4.5), and SAD (section 4.6). Our $20 \mathrm{Tg}$ simulation gives consistently too high sAOD in the tropics, midlatitudes and polar regions, whereas in most of the previous studies mentioned above, reasonable agreement is found in peak AOD, despite the high bias in stratospheric aerosol burden. We note however that there is a considerable diversity in the injection height-range, latitudinal spread and duration of the volcanic source used in these different model experiments.

The comparisons against the balloon measurements (Figs. 9 and 10) show that our model captures well the general evolution of the particle size distribution in the stratosphere through the Pinatubo period. The observations indicate how the huge injection of $\mathrm{SO}_{2}$ led after the eruption to the growth of some particles to sizes larger than $1 \mu \mathrm{m}$ at peak loading (e.g. Fig. 10b), with a long-lasting perturbation to concentrations larger than $150 \mathrm{~nm}$ causing a complex evolution of $R_{\text {eff }}$ (Fig. 8). The shift in the size distribution to 

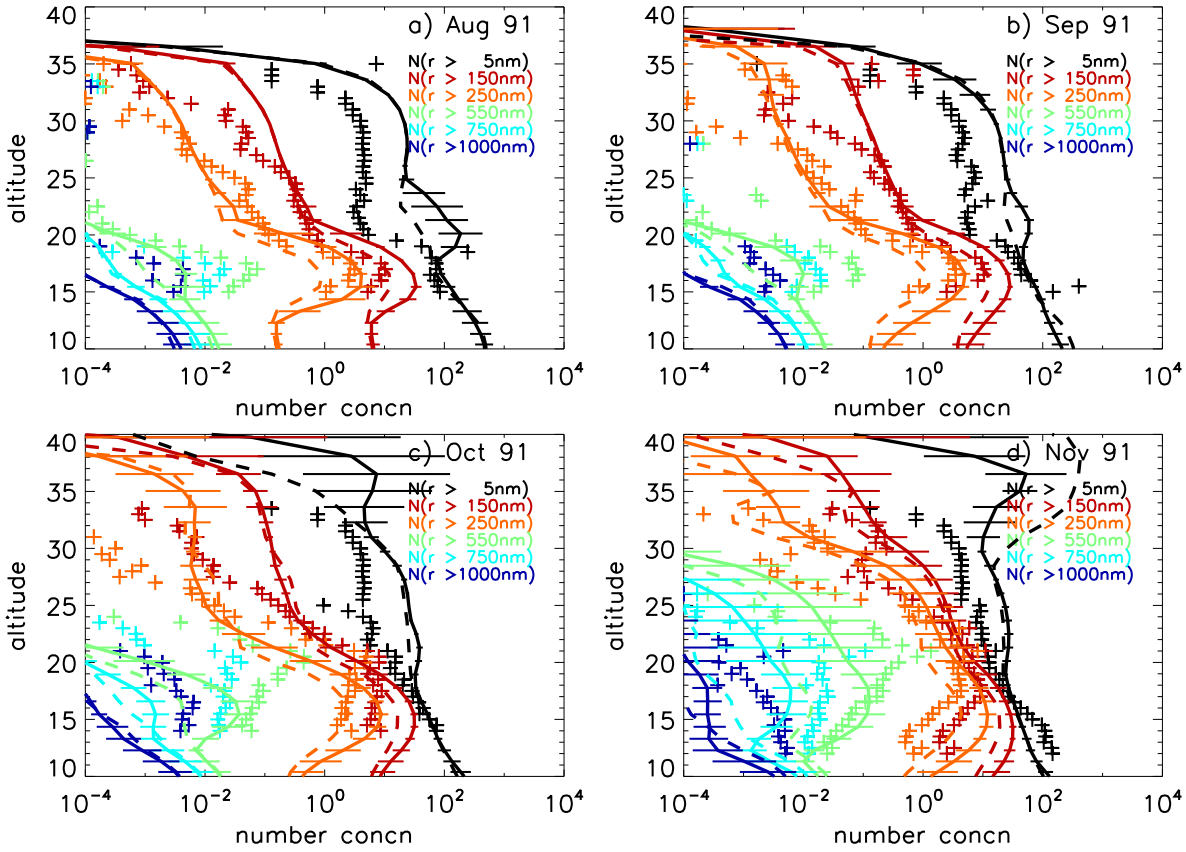

Figure 9. August, September, October, November 1991 profiles of size-resolved number concentrations of particles $\left(\mathrm{cm}^{-3}\right)$ with radii larger than $5,150,250,550,750$ and $1000 \mathrm{~nm}$ from Laramie $\left(41.3^{\circ} \mathrm{N}, 105.5^{\circ} \mathrm{W}\right)$ are shown with plus $(+)$ symbol. Solid and dashed lines show aerosol profiles from the runs A_Control20 and B_Control10, respectively, highlighting the region where the model predicts perturbation in the aerosol profiles. Horizontal coloured lines represent standard deviations $(1 \sigma)$ in number concentrations for a given month calculated from daily values for run A_Control20.
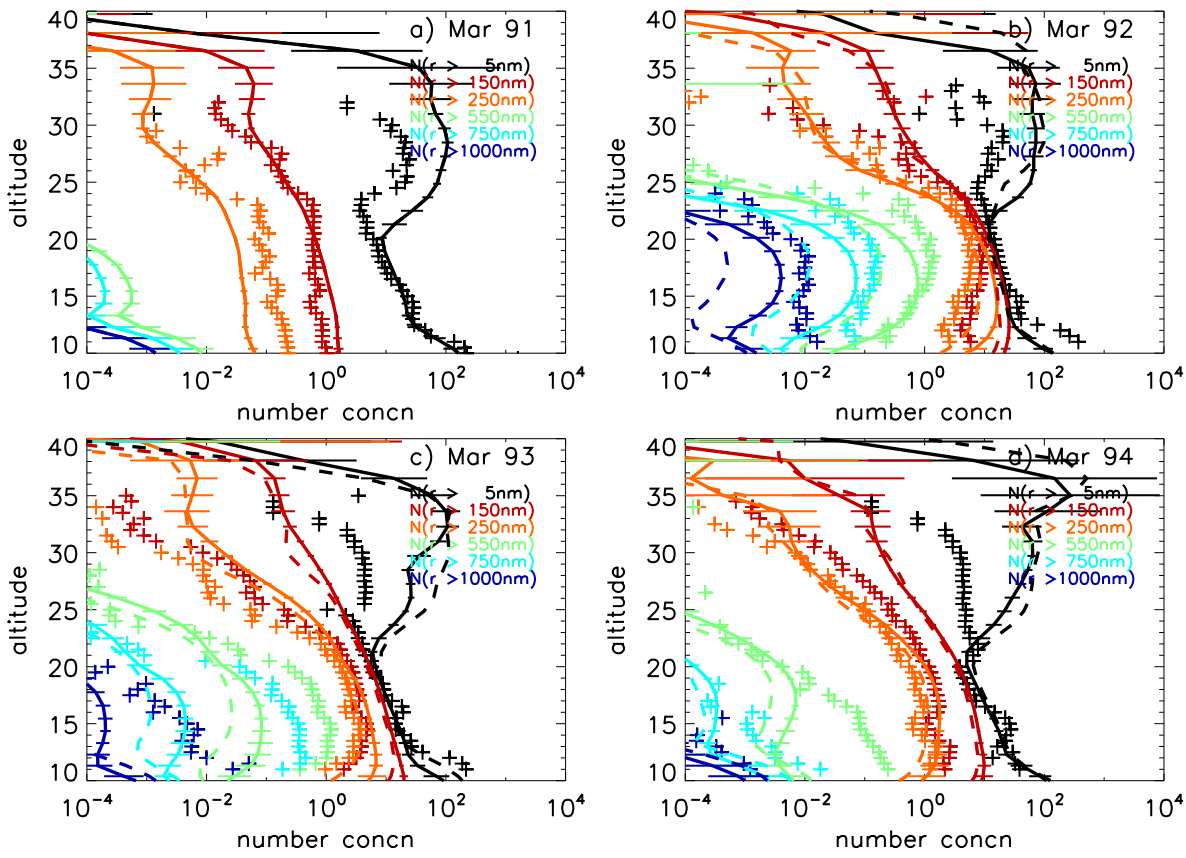

Figure 10. Same as Fig. 9 but for March 1991, March 1992, March 1993 and March 1994.

a larger $R_{\text {eff }}$ will have caused important changes in the radiative properties of the stratospheric aerosol, with significant absorption of outgoing terrestrial radiation and a decrease in the scattering efficiency of of incoming solar radiation. These altered radiative effects illustrate the importance of resolving aerosol particle size changes and subsequent feedback on 
dynamics in stratospheric CCMs, and we aim to include and assess the impact of these feedbacks in a future study (Mann et al., in prep., 2014).

Our simulations here indicate that the model is capable of capturing the main features of the observed evolution of the particle size distribution very well, with particularly good agreement with the measurements in the most perturbed posteruption period through to mid-1992. However, Fig. 10c and d suggest that the decay phase is not well captured, with $N_{150}$ reducing much more slowly than the measurements and the return to a background size distribution occurs much later in the model. We have seen that simulated particle concentrations in the 5-250 $\mathrm{nm}$ size range, whilst agreeing well in background conditions, have moderate high bias in the first year after the eruption, with the bias worsening as the model decays too slowly in the subsequent period. There are several possible causes for this model size distribution bias. It could be that the simplified modal representation of aerosol dynamics may be only partly capturing the different particle growth and removal rates across the particle size range. However, it is also worth noting that the largest biases occurred in the lowermost stratosphere and upper troposphere where STE-related processes may not be well captured in our low-resolution GCM. Another related issue is that we again note that these simulations do not include the coupling to dynamics which would increase the altitude of the aerosol layer and reduce concentrations in the lower part of the plume, where the high bias is mostly evident. Also, our model has too young age-of-air in mid-latitudes (see Fig. 1d) which may also be affecting the simulated transport and particle size evolution. Finally, we also note that nucleation rates at the very low humidity and temperature conditions in the stratosphere are known to be highly uncertain. The Vehkamäki et al. (2002) parameterisation used in this paper is the best available for stratospheric conditions, but is essentially an extrapolation from laboratory measurements at much higher temperatures and humidities, based on classical nucleation theory.

Our study is the first to fully examine the variation in simulated particle size distribution through the Pinatubo posteruption period, and we therefore choose to document the nucleation rate occurring in our simulations. Figure 11 shows, for runs A_Control20, B_Control10 and C_noPinatubo, the zonal-mean nucleation rate against latitude and altitude for monthly means through August to October 1991. In volcanically quiescent conditions (C_noPinatubo), the model has nucleation occurring mainly in the tropical upper troposphere with negligible new particle formation in the stratosphere. Note that the observed and simulated lower stratospheric $N_{5}$ and $N_{150}$ profiles at Laramie in March 1991 (Fig. 10a) are in very good agreement, and Fig. 11 indicates that these stratospheric particles were actually formed in the tropical upper troposphere, consistent with the stratospheric aerosol lifecycle described by Hamill et al. (1997). The observations at Laramie indicate that only a small proportion of these nu- cleated particles grow to sizes larger than $150 \mathrm{~nm}$, with most remaining at smaller sizes. We note however that nucleation can be seen in the middle stratosphere at $\mathrm{SH}$ mid-latitudes in the volcanically quiescent C_noPinatubo September 1991 monthly-mean, indicating the occurrence of nucleation in springtime, as seen in the McMurdo OPC record (Campbell and Deshler, 2014). Note that the mechanism here is that particle evaporation and subsequent photolysis of sulfuric acid leads to a reservoir of $\mathrm{SO}_{2}$ building up during polar winter, which leads to new particle formation in polar spring (Mills et al., 2005). This is the same mechanism that is leading to the layer of elevated $N_{5}$ at $25-30 \mathrm{~km}$ in the March Laramie profiles (see Fig. 10).

Figure 11 suggests that, following Pinatubo, strong nucleation occurred throughout the injection height range of $19-27 \mathrm{~km}$ for around 6 weeks after the eruption. Although twice as much $\mathrm{SO}_{2}$ is injected in A_Control20 than in B_Control10, the nucleation rates in the two runs are similar for July 1991. This could possibly be indicative of a depletion of oxidants which is limiting $\mathrm{SO}_{2}$ oxidation at this time, although an alternative explanation might be that there is much more surface area in the $20 \mathrm{Tg}$ injection run to act as a condensation sink for sulfuric acid vapour. Nucleation rates then reduce in magnitude through August and September as the emitted $\mathrm{SO}_{2}$ is completely converted to sulfuric acid and there is a substantial surface area to provide a condensation sink of $\mathrm{H}_{2} \mathrm{SO}_{4}$. By October 1991, nucleation rates in A_Control20 and B_Control10 have returned to similar values to those found in the quiescent C_noPinatubo simulation. Following the eruption of Mount Pinatubo, the balloon observations at Laramie indicate that, by March 1992 (e.g. Fig. 10b), $N_{150}$ is increased by a factor of 8 , whereas $N_{5}$ has already returned to pre-eruption values, consistent with the reduced nucleation rate seen here. As a consequence, $N_{5}$ and $N_{150}$ profiles are separated by only a few tens of percent, indicating that the majority of particles in the lower stratosphere have grown larger than $150 \mathrm{~nm}$ at that time. This feature was well captured by the model in runs A_Control20 and B_Control10 with the $N_{5}, N_{150}$ and $N_{250}$ profiles being remarkably similar between the two runs.

Since uptake of reactive gases is dependent on particle size, accounting for the shift in size distribution may also be important for better quantification of the influence that volcanically enhanced aerosol has on stratospheric ozone through accelerated heterogeneous chemistry. We therefore investigate the evolution of the SAD distribution across the three stratospheric aerosol modes (Fig. 12) from July 1991, 15-45 days after the eruption (panels a to d) and in October 1991, when aerosol loading was close to its peak (panels e to h). Nucleation mode particles are always smaller than $10 \mathrm{~nm}$, so even during July 1991, when substantial nucleation is occurring (Fig. 11), their contribution to total SAD is at most only around $10 \%$. However, although the Aitken mode particles are smaller than $100 \mathrm{~nm}$, during the early part of the eruption they contribute significantly to SAD in the upper 

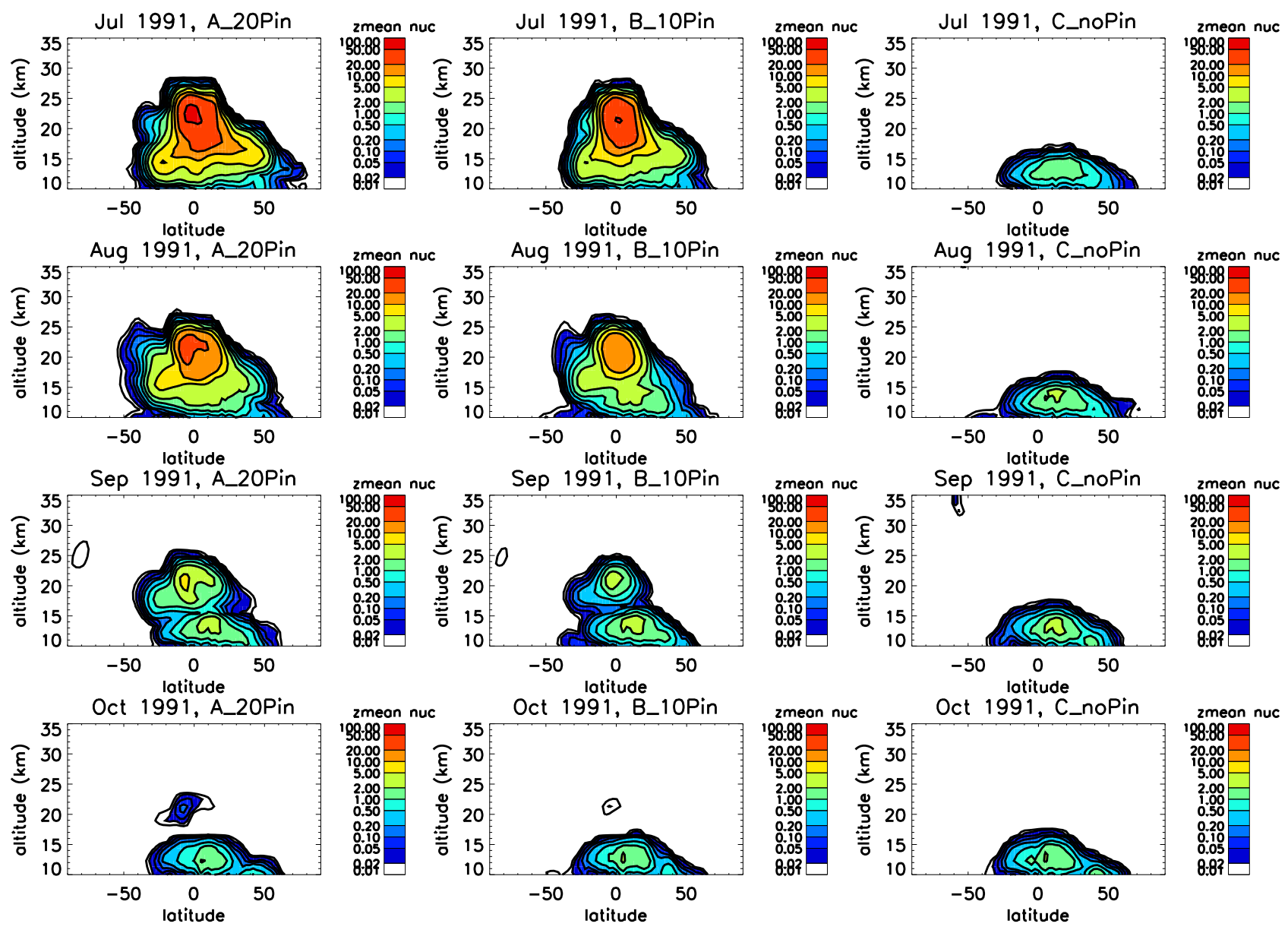

Figure 11. Modelled nucleation rates $\left(\mathrm{cm}^{3} \mathrm{~s}^{-1}\right.$ ) from runs A_Control20 (left), B_Control10 (middle), and C_noPinatubo (right) for (top to bottom) July, August, September and October 1991.

part of the plume (28 to $30 \mathrm{~km}$ ). However, the accumulation mode SAD fraction (Fig. 12c) shows that even during the early phase of eruption total SAD is primarily determined by these larger particles in the lower-middle stratosphere. At a later stage (December 1991, not shown), the contribution from nucleation and Aitken mode is insignificant and, as expected, the accumulation mode then contributes the vast majority of the SAD. We note that in Fig. 7 the model shows highest biases in simulated SAD against the observations during the first few months after the eruption.

Figure 13 compares tropical (panel a) and global (panel b) mid-visible sAOD and $N_{150}$ evolution from the three main simulations A_Control20, B_Control10 and C_noPinatubo against the satellite observations from AVHRR. We also compare time series of simulated $N_{150}$ at 18 and $22 \mathrm{~km}$ altitude against the long time series OPC measurements from Laramie. Also presented in Fig. 13 are results from two additional $10 \mathrm{Tg}$ simulations, designed to test the sensitivity of the model predictions to sub-grid particle formation (run D_noPrimary10) and with much reduced new particle formation rate (run E_ScaledStNuc10). Both of these pro- cesses are highly uncertain in the stratosphere and the two additional simulations essentially test how robust the model is to changes in the model physics. In the first 12 months after the eruption the tropical and global sAOD is around $80 \%$ higher in run A_Control20 than B_Control10, but in the second half of 1992 the difference in sAOD between the two control runs reduces to only around $10 \%$. In run D_noPrimary 10, sAOD is only very slightly lower than in B_Control10, suggesting that including the source of primary particles has only a minor impact on the aerosol evolution post-Pinatubo. The factor-100 reduced nucleation run E_ScaledStNuc10 causes a prolonged peak in tropical midvisible AOD, with values around $10 \%$ higher during September 1991, with E_ScaledStNuc10 continuing to have AOD around 5\% higher than B_Control10 through the remainder of the simulation. Intriguingly, the impact of the nucleation rate reduction on $N_{150}$ is, in the first 6 months after the eruption, to reduce $N_{150}$, which is opposite to the slight increase in mid-visible AOD. This likely is due to a reduced number of smaller particles growing to radii larger than $150 \mathrm{~nm}$, with the sAOD increase caused by larger particles which will 

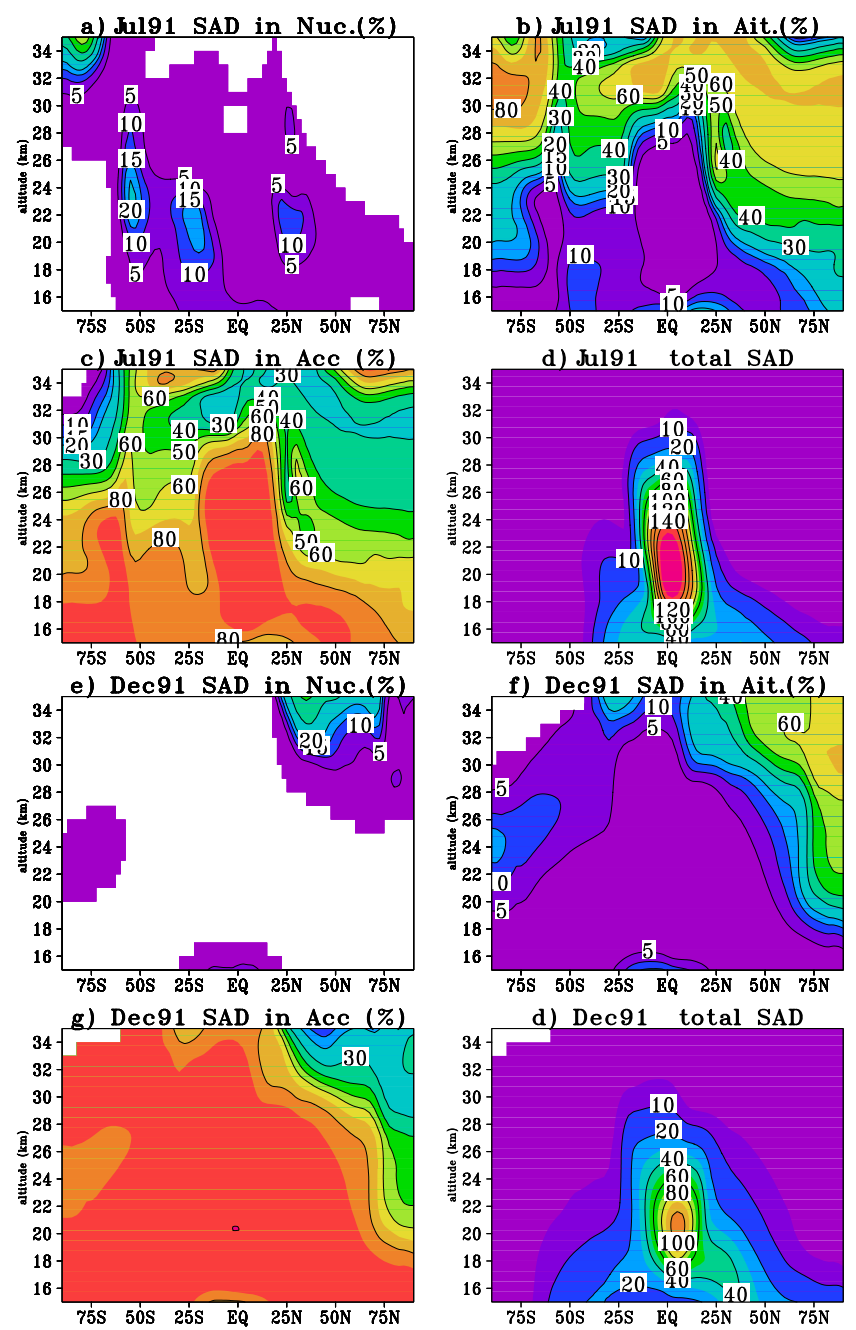

Figure 12. Percentage zonal mean surface area densities in nucleation, Aitken and accumulation modes from run A_Control20 for July 1991 (panels a, b, c) and December 1991 (panels e, f, g). Total SAD for July 1991 and December $1991\left(\mu \mathrm{m}^{2} \mathrm{~cm}^{-3}\right)$ are shown in panels (d) and (h), respectively.

have received more gas-to-particle transfer of sulfuric acid, enhancing condensational growth and increasing their scattering efficiency. In summary, however, although these microphysical sensitivities are interesting, the results suggest a low sensitivity to uncertainties in the nucleation rate, and to model treatment of sub-grid particle formation. The low sensitivity gives additional credibility to the aerosol microphysics models, suggesting the models are robust to known uncertainties in some processes in stratospheric conditions.
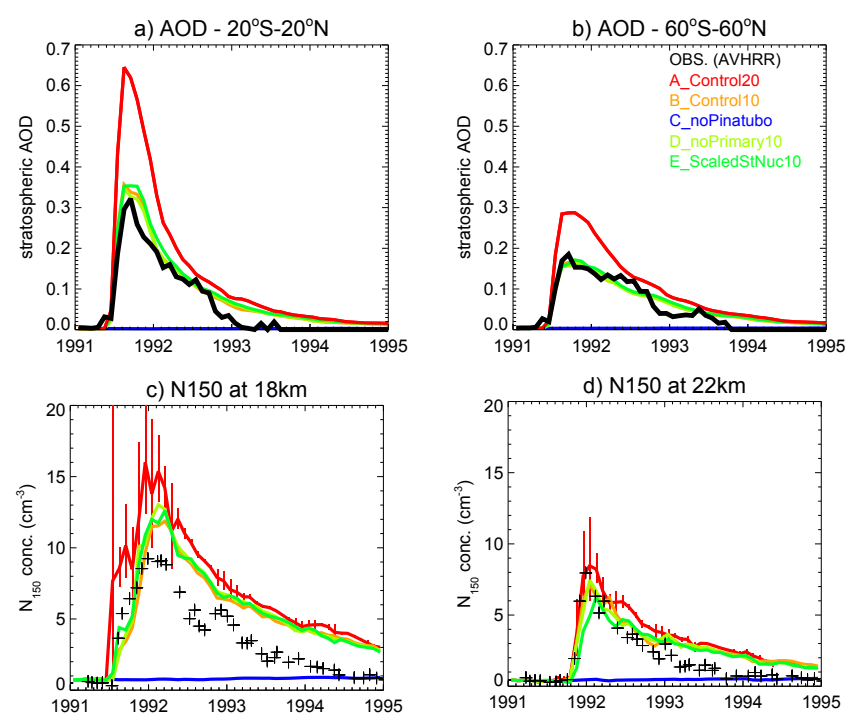

Figure 13. (a) Mean tropical $\left(20^{\circ} \mathrm{S}, 20^{\circ} \mathrm{N}\right)$ and (b) near-global $\left(60^{\circ} \mathrm{S}, 60^{\circ} \mathrm{N}\right)$ sAOD from AVHRR $(550 \mathrm{~nm})$ and various model simulations $(525 \mathrm{~nm})$. (c) and (d) show comparison between modelled and observed $N_{150}$ time series from Laramie (shown with + sign), at $18 \mathrm{~km}$ and $22 \mathrm{~km}$, respectively.

\section{Summary and conclusions}

We have extended the UM-UKCA composition-climate model to incorporate stratospheric sulfur chemistry and updated the process descriptions in the GLOMAP aerosol microphysics module to be applicable for both tropospheric and stratospheric conditions. Using stratospheric aerosol changes after the Mt Pinatubo eruption as a test case, we have evaluated simulated aerosol properties against a wide range of observations in both quiescent and volcanically perturbed conditions. The improvements to the model enable a prognostic treatment of stratospheric aerosol with dynamically varying particle size distribution alongside stratospheric transport and chemistry up to a model top of $80 \mathrm{~km}$.

In general, the model captures the observed distribution and evolution of stratospheric aerosol properties well, in both quiescent and volcanically perturbed conditions. For the Pinatubo test case, the timing of the peak in global aerosol mass and decay timescale are captured well compared to values derived from HIRS satellite measurements (Baran et al., 1993). However, our control simulation, with a $20 \mathrm{Tg}$ emission of $\mathrm{SO}_{2}$ produces much too high a burden of aerosol sulfur compared to the HIRS measurements, whereas a $10 \mathrm{Tg}$ injection is in good agreement. The $10 \mathrm{Tg}$ run also compares better to the magnitude of the enhanced SAOD distribution seen in SAGE II and AVHRR, and captures well the transport to the Southern Hemisphere. Modelled extinction in the tropical and $\mathrm{NH}$ mid-latitude lower stratosphere shows good agreement with SAGE V7 data in both the mid-visible and near-infrared. However, for the first 6 months after the 
eruption simulated SAOD and SAD are larger than the satellite measurements, and the model enhancement in $R_{\text {eff }}$ is too low (e.g. compared to Bauman et al., 2003). Lack of radiative coupling in these simulations is likely to be the dominant contribution to the high AOD, since radiative heating of the Pinatubo cloud in the tropical lower stratosphere is known to have enhanced upwelling and reduces aerosol optical depth in model simulations (e.g. Young et al., 1994).

To better understand how the particle size distribution was perturbed during the Pinatubo eruption, we have compared against mid-latitude balloon-borne measurements during that time period, allowing a strong observational constraint on concentrations of particles larger than 5, 150, 250, 550, 750 and $1000 \mathrm{~nm}$. Although there have been many model studies covering the Pinatubo period over the $22 \mathrm{yr}$ since the eruption, to our knowledge, this is the first time the full profile of a simulated size distribution in a global model has been compared to these measurements in volcanically perturbed conditions.

The model finds that in the volcanically quiescent stratosphere, nucleation occurs only during polar spring, with stratospheric particles at Laramie mostly originating from the tropical upper troposphere. In such background conditions the model agrees very well with size distribution observed at Laramie, with only a small proportion of these nucleated particles have grown to $150 \mathrm{~nm}$ by coagulation and condensation, with $N_{5}$ larger than $N_{150}$ by around a factor of 10 . We have investigated the impact on the size distribution of 20 and $10 \mathrm{Tg}$ tropical injections of $\mathrm{SO}_{2}$ from Pinatubo.

In the first 2 months after the eruption, nucleation is found to occur throughout the volcanic plume and the large injection of $\mathrm{SO}_{2}$ leads to strong growth of these particles together with growth of older particles formed in the tropical upper troposphere. Comparing the 10 and $20 \mathrm{Tg}$ control simulations, we find much larger relative difference between concentrations of particles larger than $550 \mathrm{~nm}$ between runs A_Control20 and B_Control10 than in the smaller particles between 150 and $550 \mathrm{~nm}$, which may be indicative of two types of volcanically enhanced particles. Overall the simulated profile of the particle size distribution agrees remarkably well with the observations, capturing most of the complex shape of the concentration profiles in the different size channels. However, the decay timescale for $N_{150}$ is slower in the model than the observations, which leads to an initially modest high bias increasing to around a factor of two by mid1993 (e.g. Fig. 13), with the return to a background size distribution occurring much later in the model. The spatial and temporal evolution of the $R_{\text {eff }}$ in the lower stratosphere seen by satellite (Bauman et al., 2003) is also well captured by the model, albeit with a low bias in size compared to the measurements.
Comparing the evolution and altitude of the high biases in extinction to those seen in the OPC profile measurements of the size distribution suggest that the main source of the biases is in particles in the 150 to $550 \mathrm{~nm}$ size range in the lowermost stratosphere. The discrepancy could be related to the modal aerosol dynamics failing to capture the differential growth across the particle size range. However, an alternative explanation could be that too young age-of-air and too rapid STE is affecting the simulated stratospheric aerosol evolution. We also note that enhanced upwelling from radiative heating of the enhanced aerosol layer, not included in these uncoupled simulations, will also change the vertical distribution and transport of the aerosol. It is worth noting that in radiatively coupled simulations, we expect that increased tropical upwelling would dilute the lower part of the plume, decreasing particle concentrations in the lowermost stratosphere.

Overall, the general good agreement with the size distribution measurements from Laramie and the global effective radius evolution from satellite suggest that the modal aerosol microphysics module used in our CCM is capable of representing the variation in particle size distribution in the strongly volcanically perturbed post-Pinatubo period. The sensitivity simulations also suggest that such simulated perturbations to stratospheric aerosol properties are robust to known uncertainties in nucleation rate and sub-grid particle formation. Our results underline the importance of better constraining transport and growth of Aitken-mode-sized particles in the first few months after the eruption to improve prediction of volcanic impacts on climate with stratospheric aerosol microphysics models. The findings highlight the need for a coordinated set of experiments to inter-compare and evaluate current global stratospheric aerosol models against the wide set of observations available through the Pinatuboperturbed period. 
Acknowledgements. We would like to thank P. B. Russell for effective radius data. This work was supported by the UK Natural Environment Research Council (NERC grants NE/E005659/1 and NE/E017150/1). GWM and KSC received funding from the National Centre for Atmospheric Science, one of the NERC research centres. GWM received EU funding from the European Research Council (ERC) under Seventh Framework Programme (FP7) consortium projects MACC and MACC-II (grant agreements 218793 and 283576 respectively). NB, MD, CEJ, FOC were supported as part the UK Integrated Climate Programme funded by the Department for Energy and Climate Change (DECC) and Department for Environment Food and Rural Affairs - DECC/Defra (GA01101). RH was partly funded by German Federal Ministry of Education and Research (BMBF) project ROSA (reference code 01LG1212A) within the ROMIC (Role Of the Middle Atmosphere in Climate) research programme. We would also like to thank James Keeble for his help during model development. We acknowledge use of the MONSooN system, a collaborative facility supplied under the Joint Weather and Climate Research Programme, which is a strategic partnership between the UK Met Office and the Natural Environment Research Council. This work has been also supported by NIWA as part of its Government-funded, core research programme. The in situ measurements were supported by the US National Science Foundation. Current measurements are supported under grant number ATM-0437406.

Edited by: T. Röckmann

\section{References}

Andres, R. and Kasgnoc, A.: A time-averaged inventory of subaerial volcanic sulfur emissions, J. Geophys. Res.-Atmos., 103, 2525125261, 1998.

Aquila, V., Oman, L. D., Stolarski, R. S., Colarco, P. R., and Newman, P. A.: Dispersion of the volcanic sulfate cloud from a Mount Pinatubo-like eruption, J. Geophys. Res.-Atmos., 117, D06216, doi:10.1029/2011JD016968, 2012.

Arfeuille, F., Luo, B. P., Heckendorn, P., Weisenstein, D., Sheng, J. X., Rozanov, E., Schraner, M., Brönnimann, S., Thomason, L. W., and Peter, T.: Modeling the stratospheric warming following the Mt. Pinatubo eruption: uncertainties in aerosol extinctions, Atmos. Chem. Phys., 13, 11221-11234, doi:10.5194/acp13-11221-2013, 2013.

Arnold, F., Fabian, R., and Joos, W.: Measurements of the height variation of sulfuric acid vapor concentrations in the stratosphere, Geophys. Res. Lett., 8, 293-296, 1981.

Baran, A. J. and Foot, J. S.: New application of the operational sounder HIRS in determining a climatology of sulphuric acid aerosol from the Pinatubo eruption, J. Geophys. Res.-Atmos., 99, 25673-25679, 1994.

Baran, A. J., Foot, J. S., and Dibben, P. C.: Satellite detection of volcanic sulfuric-acid aerosol, Geophys. Res. Lett., 20, 17991801, 1993.

Bauman, J., Russell, P., Geller, M., and Hamill, P.: A stratospheric aerosol climatology from SAGE II and CLAES measurements: 2. Results and comparisons, 1984-1999, J. Geophys. Res., 108, D134383, doi:10.1029/2002JD002993, 2003.
Bekki, S.: Oxidation of volcanic $\mathrm{SO}_{2}$ : a sink for stratospheric $\mathrm{OH}$ and $\mathrm{H}_{2} \mathrm{O}$, Geophys. Res. Lett., 22, 913-916, 1995.

Bekki, S. and Pyle, J.: Two dimensional assessment of the impact of aircraft sulphur emissions on the stratospheric sulphate aerosol layer, J. Geophys. Res.-Atmos., 97, 15839-15847, 1992.

Bekki, S. and Pyle, J.: A two-dimensional modeling study of the volcanic eruption of Mount Pinatubo, J. Geophys. Res.: Atmospheres (1984-2012), 99, 18861-18869, 1994.

Binkowski, F. S. and Roselle, S. J.: Models-3 Community Multiscale Air Quality (CMAQ) model aerosol component 1. Model description, J. Geophys. Res.-Atmos., 108, D64183, doi:10.1029/2001JD001409, 2003.

Bluth, G. J., Doiron, S. D., Schnetzler, C. C., Krueger, A. J., and Walter, L. S.: Global tracking of the $\mathrm{SO}_{2}$ clouds from the June, 1991 Mount Pinatubo eruptions, Geophys. Res. Lett., 19, 151154, 1992.

Bluth, G. J. S., Rose, W. I., Sprod, I. E., and Krueger, A. J.: Stratospheric loading of sulfur from explosive volcanic eruptions, Journal of Geology, 105, 671-683, 1997.

Braesicke, P., Keeble, J., Yang, X., Stiller, G., Kellmann, S., Abraham, N. L., Archibald, A., Telford, P., and Pyle, J. A.: Circulation anomalies in the Southern Hemisphere and ozone changes, Atmos. Chem. Phys., 13, 10677-10688, 2013, http://www.atmos-chem-phys.net/13/10677/2013/.

Brühl, C., Lelieveld, J., Höpfner, M., and Tost, H.: Stratospheric $\mathrm{SO}_{2}$ and sulphate aerosol, model simulations and satellite observations, Atmos. Chem. Phys. Discussions, 13, 11 395-11 425, doi:10.5194/acpd-13-11395-2013, 2013.

Campbell, P. and Deshler, T.: Condensation nuclei measurements in the midlatitude (1982-2012) and Antarctic (1986-2010) stratosphere between 20 and 35 km, J. Geophys. Res.-Atmos., 119, 137-152, 2014.

Carslaw, K. and Kärcher, B.: Stratospheric aerosol processes. In: Thomason L. and Peter Th. (Eds.) SPARC Assessment of Stratospheric Aerosol Properties (ASAP), pp. 1-28, SPARC Report No. 4, World Climate Research Programme, 2006.

Carslaw, K. S., Luo, B., and Peter, T.: An analytic expression for the composition of aqueous $\mathrm{HNO}_{3}-\mathrm{H}_{2} \mathrm{SO}_{4}$ stratospheric aerosols including gas phase removal of $\mathrm{HNO}_{3}$, Geophys. Res. Lett., 22, 1877-1880, 1995.

Carver, G. D., Brown, P. D., and Wild, O.: The ASAD atmospheric chemistry integration package and chemical reaction database, Comput. Phys. Commun., 105, 197-215, 1997.

Chipperfield, M.: New version of the TOMCAT/SLIMCAT offline chemical transport model: Intercomparison of stratospheric tracer experiments, Q. J. Roy. Meteor. Soc., 132, 1179-1203, 2006.

Chipperfield, M. and Pyle, J.: Model sensitivity studies of Arctic ozone depletion, J. Geophys. Res.-Atmos., 103, 28389-28403, 1998.

Chipperfield, M., Liang, Q., Strahan, S., Morgenstern, O., Dhomse, S., Abraham, N., Archibald, A., Bekki, S., Braesicke, P., Di Genova, G., Fleming, E. L., Hardiman, S. C., Iachetti, D., Jackman, C. H., Kinnison, D. E., Marchand, M., Pitari, G., Pyle, J. A., Rozanov, E., Stenke, A., and Tummon, F.: Multimodel estimates of atmospheric lifetimes of long-lived ozone-depleting substances: Present and future, J. Geophys. Res.-Atmos., 119, 2555-2573, 2014. 
D'Almeida, G. A., Koepke, P., and Shettle, E. P.: Atmospheric aerosols: global climatology and radiative characteristics, A. Deepak Pub. Hampton, Virginia, USA, 1991.

Damadeo, R. P., Zawodny, J. M., Thomason, L. W., and Iyer, N.: SAGE version 7.0 algorithm: application to SAGE II, Atmos. Meas. Tech. Discuss., 6, 5101-5171, doi:10.5194/amtd-6-51012013, 2013.

Dee, D. P., Uppala, S. M., Simmons, A. J., Berrisford, P., Poli, P., Kobayashi, S., Andrae, U., Balmaseda, M. A., Balsamo, G., Bauer, P., Bechtold, P., Beljaars, A. C. M., van de Berg, L., Bidlot, J., Bormann, N., Delsol, C., Dragani, R., Fuentes, M., Geer, A. J., Haimberger, L., Healy, S., Hersbach, H., Holm, E. V., Isaksen, L., Kallberg, P., Koehler, M., Matricardi, M., McNally, A. P., Monge-Sanz, B. M., Morcrette, J.-J., Peubey, C., de Rosnay, P., Tavolato, C., Thapaut, J.-N., and Vitart, F.: The ERA-Interim reanalysis: Configuration and performance of the data assimilation system, Q. J. R. Meteor. Soc., 133, 1972-1990, 2011.

Deshler, T.: In situ measurements of Pinatubo aerosol over Kiruna on four days between 18 January and 13 February 1992, Geophys. Res. Lett., 21, 1323-1326, 1994.

Deshler, T.: A review of global stratospheric aerosol: Measurements, importance, life cycle, and local stratospheric aerosol, Atmospheric Research, 90, 223-232, 2008.

Deshler, T., Hofmann, D., Johnson, B., and Rozier, W.: Balloonborne measurements of the Pinatubo aerosol size distribution and volatility at Laramie, Wyoming during the summer of 1991, Geophys. Res. Lett., 19, 199-202, 1992.

Deshler, T., Johnson, B. J., and Rozier, W. R.: Balloonborne measurements of Pinatubo aerosol during 1991 and 1992 at $41^{\circ} \mathrm{N}$ : Vertical profiles, size distribution, and volatility, Geophys. Res. Lett., 20, 1435-1438, doi:10.1029/93GL01337, 1993.

Deshler, T., Hervig, M. E., Hofmann, D. J., Rosen, J. M., and Liley, J. B.: Thirty years of in situ stratospheric aerosol size distribution measurements from Laramie, Wyoming (41 degrees $\mathrm{N}$ ), using balloon-borne instruments, J. Geophys. Res.-Atmos., 108, D54167, doi:10.1029/2002JD002514, 2003.

Dhomse, S., Weber, M., Wohltmann, I., Rex, M., and Burrows, J. P.: On the possible causes of recent increases in northern hemispheric total ozone from a statistical analysis of satellite data from 1979 to 2003, Atmos. Chem. Phys., 6, 1165-1180, doi:10.5194/acp-6-1165-2006, 2006.

Driscoll, S., Bozzo, A., Gray, L. J., Robock, A., and Stenchikov, G.: Coupled Model Intercomparison Project 5 (CMIP5) simulations of climate following volcanic eruptions, J. Geophys. Res.Atmos., 117, D17105, doi:10.1029/2012JD017607, 2012.

English, J. M., Toon, O. B., and Mills, M. J.: Microphysical simulations of sulfur burdens from stratospheric sulfur geoengineering, Atmos. Chem. Phys., 12, 4775-4793, doi:10.5194/acp-12-47752012, 2012.

English, J. M., Toon, O. B., and Mills, M. J.: Microphysical simulations of large volcanic eruptions: Pinatubo and Toba, J. Geophys. Res.-Atmos., 118, 1880-1895, doi:10.1002/jgrd.50196, 2013.

Graf, H. F., Kirchner, I., Robock, A., and Schult, I.: Pinatubo eruption winter climate effects: Model versus observations, Clim. Dynam., 9, 81-93, 1993.

Grainger, R., Lambert, A., Taylor, F., Remedios, J., Rodgers, C., Corney, M., and Kerridge, B.: Infrared absorption by volcanic stratospheric aerosols observed by ISAMS, Geophys. Res. Lett., 20, 1283-1286, 1993.
Guo, S., Bluth, G. J., Rose, W. I., Watson, I. M., and Prata, A.: Reevaluation of SO2 release of the 15 June 1991 Pinatubo eruption using ultraviolet and infrared satellite sensors, Geochem. Geophy. Geosys., 5, Q04001, doi:10.1029/2003GC000654, 2004a.

Guo, S., Rose, W. I., Bluth, G. J., and Watson, I. M.: Particles in the great Pinatubo volcanic cloud of June 1991: The role of ice, Geochem. Geophy. Geosys., 5, Q05003, doi:10.1029/2003GC000655, 2004b.

Hall, T. M., Waugh, D. W., Boering, K. A., and Plumb, R. A.: Evaluation of transport in stratospheric models, J. Geophys. Res.Atmos., 104, 18815-18839, 1999.

Hamill, P., Jensen, E. J., Russell, P., and Bauman, J. J.: The life cycle of stratospheric aerosol particles, B. Am. Meteorol. Soc., 78, 1395-1410, 1997.

Hamill, P., Brogniez, C., Thomason, L., Deshler, T., Antuña, J., Baumgardner, D., Bevilacqua, R., Brock, C., David, C., Fussen, D., Hervig, M., Hostettler, C. A., Lee, S.-H., Mergenthaler, J., Osborn, M. T., Raga, G., Reeves, J. M., Rosen, J., and Wilson, J. C.: Instrument Descriptions, edited by: Thomason, L. and Peter, Th., SPARC Assessment of Stratospheric Aerosol Properties (ASAP), 77-106, SPARC Report No. 4, World Climate Research Programme, 2006.

Hansen, J., Lacis, A., Ruedy, R., and Sato, M.: Potential climate impact of Mount Pinatubo eruption, Geophys. Res. Lett., 19, 215 218, 1992.

Hewitt, H. T., Copsey, D., Culverwell, I. D., Harris, C. M., Hill, R. S. R., Keen, A. B., McLaren, A. J., and Hunke, E. C.: Design and implementation of the infrastructure of HadGEM3: the nextgeneration Met Office climate modelling system, Geosci. Model Dev., 4, 223-253, doi:10.5194/gmd-4-223-2011, 2011.

Hofmann, D. and Rosen, J.: Balloo-sorne observations of stratospheric aerosol and condensation nuclei during the year following the Mt. St. Helens eruption, J. Geophys. Res.-Ocean, 87, 11039-11061, 1982.

Hofmann, D. and Rosen, J.: On the temporal variation of stratospheric aerosol size and mass during the first 18 months following the 1982 eruptions of El Chichón, J. Geophys. Res.-Atmos, 89, 4883-4890, 1984.

Holton, J. R. and Tan, H.-C.: The influence of the equatorial quasibiennial oscillation on the global circulation at $50 \mathrm{mb}$, J. Atmos. Sci., 37, 2200-2208, 1980.

Holton, J. R., Haynes, P. H., McIntyre, M. E., Douglass, A. R., Rood, R. B., and Pfister, L.: Stratosphere-troposphere exchange, Rev. Geophys., 33, 403-439, 1995.

Hommel, R., Timmreck, C., and Graf, H.: The global middleatmosphere aerosol model MAECHAM5-SAM2: comparison with satellite and in-situ observations, Geosci. Model Dev., 4, 809-834, doi:10.5194/gmd-4-809-2011, 2011.

Hurrell, J. W., Hack, J. J., Shea, D., Caron, J. M., and Rosinski, J.: A new sea surface temperature and sea ice boundary dataset for the Community Atmosphere Model, J. Climate, 21, 5145-5153, 2008.

Jones, C., Hughes, J., Bellouin, N., Hardiman, S., Jones, G., Knight, J., Liddicoat, S., O'Connor, F., Andres, R. J., and Bell, C.: The HadGEM2-ES implementation of CMIP5 centennial simulations, Geosci. Model Dev., 4, 543-570, 2011.

Kerminen, V.-M. and Kulmala, M.: Analytical formulae connecting the "real" and the "apparent" nucleation rate and the nuclei num- 
ber concentration for atmospheric nucleation events, J. Aerosol Sci., 33, 609-622, 2002.

Kettle, A. and Andreae, M.: Flux of dimethylsulfide from the oceans: A comparison of updated data sets and flux models, J. Geophys. Res.-Atmos., 105, 26793-26808, 2000.

Kokkola, H., Hommel, R., Kazil, J., Niemeier, U., Partanen, A.-I., Feichter, J., and Timmreck, C.: Aerosol microphysics modules in the framework of the ECHAM5 climate model - intercomparison under stratospheric conditions, Geosci. Model Dev., 2, 97-112, doi:10.5194/gmd-2-97-2009, 2009.

Kreidenweis, S. M., Walcek, C. J., Feingold, G., Gong, W., Jacobson, M. Z., Kim, C.-H., Liu, X., Penner, J. E., Nenes, A., and Seinfeld, J. H.: Modification of aerosol mass and size distribution due to aqueous-phase SO2 oxidation in clouds: Comparisons of several models, J. Geophys. Res., 108, D74213, doi:10.1029/2002JD002697, 2003.

Kulmala, M. and Laaksonen, A.: Binary nucleation of watersulfuric acid system: Comparison of classical theories with different $\mathrm{H}_{2} \mathrm{SO}_{4}$ saturation vapor pressures, J. Chem. Phys., 93, 696, 1990.

Kulmala, M., Laaksonen, A., and Pirjola, L.: Parameterizations for sulfuric acid/water nucleation rates, J. Geophys. Res.-Atmos., 103, 8301-8307, 1998.

Labitzke, K. and McCormick, M.: Stratospheric temperature increases due to Pinatubo aerosols, Geophys. Res. Lett., 19, 207210, 1992.

Lacis, A., Hansen, J., and Sato, M.: Climate forcing by stratospheric aerosols, Geophys. Res. Lett., 19, 1607-1610, 1992.

Lamarque, J.-F., Bond, T. C., Eyring, V., Granier, C., Heil, A., Klimont, Z., Lee, D., Liousse, C., Mieville, A., Owen, B., Schultz, M. G., Shindell, D., Smith, S. J., Stehfest, E., Van Aardenne, J., Cooper, O. R., Kainuma, M., Mahowald, N., McConnell, J. R., Naik, V., Riahi, K., and van Vuuren, D. P.: Historical (1850-2000) gridded anthropogenic and biomass burning emissions of reactive gases and aerosols: methodology and application, Atmos. Chem. Phys., 10, 7017-7039, doi:10.5194/acp10-7017-2010, 2010.

Lambert, A., Grainger, R., Remedios, J., Rodgers, C., Corney, M., and Taylor, F.: Measurements of the evolution of the Mt. Pinatubo aerosol cloud by ISAMS, Geophys. Res. Lett., 20, 1287-1290, 1993.

Liss, P. S. and Merlivat, L.: Air-sea gas exchange rates: Introduction and synthesis, 113-127, Springer, Netherlands, 1986.

Long, C. S. and Stowe, L. L.: Using the NOAA/AVHRR to study stratospheric aerosol optical thicknesses following the Mt. Pinatubo eruption, Geophys. Res. Lett., 21, 2215-2218, 1994.

Mann, G., Carslaw, K., Spracklen, D., Ridley, D., Manktelow, P., Chipperfield, M., Pickering, S., and Johnson, C.: Description and evaluation of GLOMAP-mode: a modal global aerosol microphysics model for the UKCA composition-climate model, Geosci. Model Dev., 3, 519-551, 2010.

Mann, G. W., Carslaw, K. S., Ridley, D. A., Spracklen, D. V., Pringle, K. J., Merikanto, J., Korhonen, H., Schwarz, J. P., Lee, L. A., Manktelow, P. T., Woodhouse, M. T., Schmidt, A., Breider, T. J., Emmerson, K. M., Reddington, C. L., Chipperfield, M. P., and Pickering, S. J.: Intercomparison of modal and sectional aerosol microphysics representations within the same 3-D global chemical transport model, Atmos. Chem. Phys., 12, 4449-4476, doi:10.5194/acp-12-4449-2012, 2012.
Martin, E., George, C., and Mirabel, P.: Densities and surface tensions of $\mathrm{H}_{2} \mathrm{SO}_{4} / \mathrm{HNO}_{3} / \mathrm{H}_{2} \mathrm{O}$ solutions, Geophys. Res. Lett., 27, 197-200, 2000.

McCormick, M. and Veiga, R.: SAGE II measurements of early Pinatubo aerosols, Geophys. Res. Lett., 19, 155-158, 1992.

McCormick, M. P., Thomason, L. W., and Trepte, C. R.: Atmospheric effects of the Mt Pinatubo eruption, Nature, 373, 399404, 1995.

Mills, M. J., Toon, O. B., Vaida, V., Hintze, P. E., Kjaergaard, H. G., Schofield, D. P., and Robinson, T. W.: Photolysis of sulfuric acid vapor by visible light as a source of the polar stratospheric CN layer, J. Geophys. Res.-Atmos., 110, D08201, doi:10.1029/2004JD005519D8, 2005.

Montzka, S., Calvert, P., Hall, B., Elkins, J., Conway, T., Tans, P., and Sweeney, C.: On the global distribution, seasonality, and budget of atmospheric carbonyl sulfide (COS) and some similarities to CO2, J. Geophys. Res.-Atmos., 112, D09302, doi:10.1029/2006JD007665, 2007.

Morgenstern, O., Braesicke, P., O’Connor, F., Bushell, A., Johnson, C., Osprey, S., and Pyle, J.: Evaluation of the new UKCA climate-composition model Part 1: The stratosphere, Geosci. Model Dev., 2, 43-57, 2009.

Neu, J. L., Prather, M. J., and Penner, J. E.: Global atmospheric chemistry: Integrating over fractional cloud cover, J. Geophys. Res.-Atmos., 112, D11306, doi:10.1029/2006JD008007, 2007.

Niemeier, U., Timmreck, C., Graf, H.-F., Kinne, S., Rast, S., and Self, S.: Initial fate of fine ash and sulfur from large volcanic eruptions, Atmos. Chem. Phys., 9, 9043-9057, doi:10.5194/acp9-9043-2009, 2009.

Oman, L., Robock, A., Stenchikov, G. L., Thordarson, T., Koch, D., Shindell, D. T., and Gao, C. C.: Modeling the distribution of the volcanic aerosol cloud from the 17831784 Laki eruption, J. Geophys. Res.-Atmos., 111, D12209, doi:10.1029/2005JD006899, 2006.

Pitari, G. and Mancini, E.: Short-term climatic impact of the 1991 volcanic eruption of Mt. Pinatubo and effects on atmospheric tracers, Natural Hazards and Earth System Science, 2, 91-108, doi:10.5194/nhess-2-91-2002, 2002.

Reeves, J., Wilson, J., Brock, C., and Bui, T.: Comparison of aerosol extinction coefficients, surface area density, and volume density from SAGE II and in situ aircraft measurements, J. Geophys. Res.-Atmos., 113, D10202, doi:10.1029/2007JD009357113, 2008.

Robock, A.: Volcanic eruptions and climate, Rev. Geophys., 38, 191-219, 2000.

Robock, A. and Mao, J.: Winter warming from large volcanic eruptions, Geophys. Res. Lett., 19, 2405-2408, 1992.

Rosen, J. M.: The vertical distribution of dust to 30 kilometers, J. Geophys. Res., 69, 4673-4676, 1964.

Russell, P., Livingston, J., Pueschel, R., Bauman, J., Pollack, J., Brooks, S., Hamill, P., Thomason, L., Stowe, L., and Deshler, T.: Global to microscale evolution of the Pinatubo volcanic aerosol derived from diverse measurements and analyses, J. Geophys. Res., 101, 18745-18763, 1996.

Sander, S., Friedl, R., Golden, D., Kurylo, M., Huie, R., Orkin, V., Moortgat, G., Wine, P., Ravishankara, A., Kolb, C., Molina, M., Finlayson-Pitts, B., Huie, R., Orkin, V. L., and Keller-Rudek, H.: Chemical kinetics and photochemical data for use in atmospheric studies, NASA Panel for Data Evaluation, Evaluation number 15, 
JPL Publication 06-2, Vol. 4915, Jet Propulsion Laboratory, California Insitute of Technology, Pasadena, California, 2006.

Sato, M., Hansen, J. E., McCormick, M. P., and Pollack, J. B.: Stratospheric aerosol optical depths, 1850-1990, J. Geophys. Res.-Atmos., 98, 22987-22994, 1993.

Saunders, R. W., Dhomse, S., Tian, W. S., Chipperfield, M. P., and Plane, J. M. C.: Interactions of meteoric smoke particles with sulphuric acid in the Earth's stratosphere, Atmos. Chem. Phys., 12, 4387-4398, doi:10.5194/acp-12-4387-2012, 2012.

Scaife, A. A., Spangehl, T., Fereday, D. R., Cubasch, U., Langematz, U., Akiyoshi, H., Bekki, S., Braesicke, P., Butchart, N., and Chipperfield, M. P.: Climate change projections and stratospheretroposphere interaction, Clim. Dynam., 38, 2089-2097, 2012.

Solomon, S., Portmann, R. W., Garcia, R. R., Thomason, L. W., Poole, L. R., and McCormick, M. P.: The role of aerosol variations in anthropogenic ozone depletion at northern midlatitudes, J. Geophys. Res.-Atmos., 101, 6713-6727, 1996.

Solomon, S., Daniel, J., Neely, R., Vernier, J.-P., Dutton, E., and Thomason, L.: The persistently variable background stratospheric aerosol layer and global climate change, Science, 333, 866-870, 2011.

SPARC: SPARC Assessment of stratospheric aerosol properties (ASAP), SPARC Report No. 4, World Clim. Res. Programme, WCRP-124, WMO/TD-No.1295, 2006.

SPARC: SPARC Report on the Evaluation of Chemistry-Climate Models, World Clim. Res. Programme, WCRP-132, WMO/TDNo.1526, 2010.

SPARC: SPARC Report on Lifetimes of Stratospheric OzoneDepleting Substances, Their Replacements, and Related Species, SPARC Report No. 6, World Clim. Res. Programme, WCRP15/2013, 2013.

Spracklen, D. V., Pringle, K. J., Carslaw, K. S., Chipperfield, M. P., and Mann, G. W.: A global off-line model of size-resolved aerosol microphysics: I. Model development and prediction of aerosol properties, Atmos. Chem. Phys., 5, 2227-2252, doi:10.5194/acp-5-2227-2005, 2005.

Stenchikov, G. L., Kirchner, I., Robock, A., Graf, H., Antuna, J. C., Grainger, R., Lambert, A., and Thomason, L.: Radiative forcing from the 1991 Mount Pinatubo volcanic eruption, J. Geophys. Res.-Atmos., 103, 13837-13857, 1998.

Stier, P., Feichter, J., Kinne, S., Kloster, S., Vignati, E., Wilson, J., Ganzeveld, L., Tegen, I., Werner, M., Balkanski, Y., Schulz, M., Boucher, O., Minikin, A., and Petzold, A.: The aerosol-climate model ECHAM5-HAM, Atmos. Chem. Phys., 5, 1125-1156, doi:10.5194/acp-5-1125-2005, 2005.

Stokes, R. and Robinson, R.: Interactions in aqueous nonelectrolyte solutions. I. Solute-solvent equilibria, J. Phys. Chem., 70, 21262131, 1966.

Strahan, S. E., Douglass, A. R., Stolarski, R. S., Akiyoshi, H., Bekki, S., Braesicke, P., Butchart, N., Chipperfield, M. P., Cugnet, D., Dhomse, S., Frith, S. M., Gettelman, A., Hardiman, S. C., Kinnison, D. E., Lamarque, J. F., Mancini, E., Marchand, M., Michou, M., Morgenstern, O., Nakamura, T., Olivie, D., Pawson, S., Pitari, G., Plummer, D. A., Pyle, J. A., Scinocca, J. F., Shepherd, T. G., Shibata, K., Smale, D., Teyssedre, H., Tian, W., and Yamashita, Y.: Using transport diagnostics to understand chemistry climate model ozone simulations, J. Geophys. Res.Atmos., 116, D17302, doi:doi:10.1029/2010JD015360, 2011.
Taylor, K. E., Stouffer, R. J., and Meehl, G. A.: An overview of CMIP5 and the experiment design, B. Am. Meteorol. Soc., 93, 485-498, 2012.

Telford, P., Abraham, N., Archibald, A., Braesicke, P., Dalvi, M., Morgenstern, O., O'Connor, F., Richards, N., and Pyle, J.: Implementation of the Fast-JX Photolysis scheme (v6. 4) into the UKCA component of the MetUM chemistry-climate model (v7. 3), Geosci. Model Dev., 6, 161-177, 2013.

Textor, C., Schulz, M., Guibert, S., Kinne, S., Balkanski, Y., Bauer, S., Berntsen, T., Berglen, T., Boucher, O., Chin, M., Dentener, F., Diehl, T., Easter, R., Feichter, H., Fillmore, D., Ghan, S., Ginoux, P., Gong, S., Grini, A., Hendricks, J., Horowitz, L., Huang, P., Isaksen, I., Iversen, I., Kloster, S., Koch, D., Kirkevåg, A., Kristjansson, J. E., Krol, M., Lauer, A., Lamarque, J. F., Liu, X., Montanaro, V., Myhre, G., Penner, J., Pitari, G., Reddy, S., Seland, Ø., Stier, P., Takemura, T., and Tie, X.: Analysis and quantification of the diversities of aerosol life cycles within AeroCom, Atmos. Chem. Phys., 6, 1777-1813, doi:10.5194/acp-6-1777-2006, 2006.

Thomason, L., Poole, L., and Deshler, T.: A global climatology of stratospheric aerosol surface area density deduced from Stratospheric Aerosol and Gas Experiment II measurements 1984 1994, J. Geophys. Res.-Atmos., 102, 8967-8976, 1997.

Timmreck, C.: Three-dimensional simulation of stratospheric background aerosol: First results of a multiannual general circulation model simulation, J. Geophys. Res.-Atmos., 106, 28313-28332, 2001.

Timmreck, C., Graf, H.-F., and Feichter, J.: Simulation of Mt. Pinatubo volcanic aerosol with the Hamburg climate model ECHAM4, Theor. Appl. Climatol., 62, 85-108, 1999.

Toohey, M., Krüger, K., Niemeier, U., and Timmreck, C.: The influence of eruption season on the global aerosol evolution and radiative impact of tropical volcanic eruptions, Atmos. Chem. Phys., 11, 12351-12367, doi:10.5194/acp-11-12351-2011, 2011.

Trepte, C. R. and Hitchman, M. H.: Tropical stratospheric circulation deduced from satellite aerosol data, Nature, 355, 626-628, 1992.

Vehkamäki, H., Kulmala, M., Napari, I., Lehtinen, K. E., Timmreck, C., Noppel, M., and Laaksonen, A.: An improved parameterization for sulfuric acid-water nucleation rates for tropospheric and stratospheric conditions, J. Geophys. Res., 107, D224622, doi:10.1029/2002JD002184, 2002.

Vignati, E., Wilson, J., and Stier, P.: M7: An efficient size Resolved aerosol microphysics module for large scale aerosol transport models, J. Geophys. Res.-Atmos., 109, D22202, doi:10.1029/2003JD004485, 2004.

Weber, M., Dhomse, S., Wittrock, F., Richter, A., Sinnhuber, B. M., and Burrows, J. P.: Dynamical control of NH and SH winter/spring total ozone from GOME observations in 1995-2002, Geophys. Res. Lett., 30, 2003.

Weisenstein, D., Bekki, S., Mills, M., Pitari, G., and Timmreck, C.: Modeling of stratospheric aerosols, edited by: Thomason, L. and Peter, Th., SPARC Assessment of Stratospheric Aerosol Properties (ASAP), 219-272, SPARC Report No. 4, World Climate Research Programme, 2006.

Weisenstein, D. K., Yue, G. K., Ko, M. K. W., Sze, N. D., Rodriguez, J. M., and Scott, C. J.: A two-dimensional model of sulfur species and aerosols, J. Geophys. Res.-Atmos., 102, 1301913035, 1997. 
Wild, O., Zhu, X., and Prather, M. J.: Fast-J: Accurate simulation of in-and below-cloud photolysis in tropospheric chemical models, J. Atmos. Chem., 37, 245-282, 2000.

Wilson, J., Cuvelier, C., and Raes, F.: A modeling study of global mixed aerosol fields, J. Geophys. Res.-Atmos., 106, 3408134108, 2001.

WMO: Scientific Assessment of Ozone Depletion: 2010, Global Ozone Research and Monitoring Project Report 52, World Meteorological Organization, Geneva, 2011.
Young, R. E., Houben, H., and Toon, O. B.: Radiatively forced dispersion of the Mt. Pinatubo volcanic cloud and induced temperature perturbations in the stratosphere during the first few months following the eruption, Geophys. Res. Lett., 21, 369-372, 1994.

Zdanovskii, A.: New methods for calculating solubilities of electrolytes in multicomponent systems, Zh. Fiz. Khim, 22, 14751485, 1948. 